\title{
Blood Flow Mediated Hybrid Nanoparticles in Human Arterial System: Recent Research, Development and Applications
}

\author{
Jayati Tripathi ${ }^{1}$, B. Vasu ${ }^{1, *}$, Rama Subba Reddy Gorla ${ }^{2}$, Ali J. Chamkha ${ }^{3}$, \\ P. V. S. N. Murthy ${ }^{4}$, and O. Anwar Bég ${ }^{5}$ \\ ${ }^{1}$ Department of Mathematics, Motilal Nehru National Institute of Technology Allahabad, Prayagraj 211004, U.P., India \\ ${ }^{2}$ Department of Aeronautics and Astronautics, Air Force Institute of Technology, Wright Patterson Air Force Base, \\ Dayton, Ohio, 45433, USA \\ ${ }^{3}$ Faculty of Engineering, Kuwait College of Science and Technology, Doha District, 35004, Kuwait \\ ${ }^{4}$ Department of Mathematics, Indian Institute of Technology Kharagpur, Kharagpur 721302, India \\ ${ }^{5}$ Department of Mechanical and Aeronautical Engineering, Salford University, Salford, M54WT, UK
}

Blood flow dynamics contributes an elemental part in the formation and expansion of cardiovascular diseases in human body. Computational simulation of blood flow in the human arterial system has been widely used in recent decades for better understanding the symptomatic spectrum of various diseases, in order to improve already existing or develop new therapeutic techniques. The characteristics of the blood flow in an artery can be changed significantly by arterial diseases, such as aneurysms and stenoses. The progress of atherosclerosis or stenosis in a blood vessel is quite common which may be caused due to the addition of lipids in the arterial wall. Nanofluid is a colloidal mixture of nanometer sized (which ranges from 10-100 m) metallic and nonmetallic particles in conventional fluid (such as water, oil). The delivery of nanoparticles is an interesting and growing field in the development of diagnostics and remedies for blood flow complications. An enhancement of nano-drug delivery performance in biological systems, nanoparticles properties such as size, shape and surface characteristics can be regulated. Nanoparticle offers remarkably advantages over the traditional drug delivery in terms of high specificity, high stability, high drug carrying capacity, ability for controlled release. Highly dependency has been found for their behavior under blood flow while checking for their ability to target and penetrate tissues from the blood. In the field of nano-medicine, organic (including polymeric micelles and vesicles, liposomes) and inorganic (gold and mesoporous silica, copper) nanoparticles have been broadly studied as particular carriers because as drug delivery systems they delivered a surprising achievement as a result of their biocompatibility with tissue and cells, their subcellular size, decreased toxicity and sustained release properties. For the extension of nanofluids research, the researchers have also tried to use hybrid nanofluid recently, which is synthesized by suspending dissimilar nanoparticles either in mixture or composite form. The main idea behind using the hybrid nanofluid is to further improve the heat transfer and pressure drop characteristics. Nanoparticles are helpful as drug carriers to minimize the effects of resistance impedance to blood flow or coagulation factors due to stenosis. Discussed various robust approaches have been employed for the nanoparticle transport through blood in arterial system. The main objective of the paper is to provide a comprehensive review of computational simulations of blood flow containing hybrid-nanoparticles as drug carriers in the arterial system of the human body. The recent developments and analysis of convective flow of particle-fluid suspension models for the axi-symmetric arterial bodies in hemodynamics are summarized. Detailed existing mathematical models for simulating blood flow with nanoparticles in stenotic regions are reviewed. The review focuses on selected numerical simulations of physiological convective flows under various stenosis approximations and computation of the temperature, velocity, resistance impedance to flow, wall shear stress and the pressure gradient with the corresponding boundary conditions. The current review also highlights

\footnotetext{
Author to whom correspondence should be addressed.

Email: bvasu@mnnit.ac.in

Received: 14 April 2021

Accepted: 6 May 2021
} 
that the drug carrier nanoparticles are efficient mechanisms for reducing hemodynamics of stenosis and could be helpful for other biomedical applications. The review considers flows through various stenoses and the significances of numerical fluid mechanics in clinical medicine. The review examines nano-drug delivery systems, nanoparticles and describes recent computational simulations of nano-pharmacodynamics.

KEYWORDS: Blood Flow, Stenotic Artery, Nanofluids, Drug-Carrier, Single-Phase Modeling, Pharmacodynamics, Numerical Simulations.

\section{CONTENTS}

\section{Introduction}

1.1. Blood Flow in Arterial System . . . . . . . . . . . . . . . . . 4

1.2. Models for Blood Flow . . . . . . . . . . . . . . . 6

2. Nanofluids: Recent Research, Development and Applications . . 7

2.1. Nanofluids . . . . . . . . . . . . . . . . 7

2.2. Hybrid Nanofluids . . . . . . . . . . . . . . . . . . . . . . . . . 8

2.3. Physical Models . . . . . . . . . . . . . . . . . . 9

2.4. Review of Hybrid Nanofluids . . . . . . . . . . . . 14

2.5. Rheological Behavior of Nanofluids . . . . . . . . . . 14

3. Review of Computational Bio-Nano Fluid Flows . . . . . . . 18

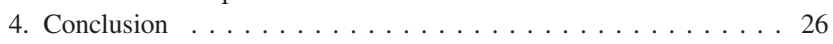

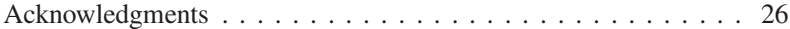

References and Notes . . . . . . . . . . . . . . 26

\section{INTRODUCTION}

The main function of the blood circulatory system, an impenetrable network of blood vessels, is to transport vital nutrients and oxygen to the active tissues of the body and remove waste products. This system is responsible for the exchange of ions, cells, gases and macromolecules between the blood and tissue. Blood flow dynamics contributes an elemental part in the formation and expansion of cardiovascular diseases. Accumulation of macrophage white blood cells, low-density lipoproteins
(LDL), cholesterol to the arterial wall of blood vessels is referred to as a hardening of the arteries, which results in a reduction in the area of the blood vessel and leads to the cardiovascular diseases (Fig. 1). Nowadays, in many countries, the majority of deaths are being reported because of this disease. For the improvement of already existing techniques or for the development of new therapeutic methods, simulation of blood flow is being widely used in present decades to better understand the numerous diseases. The most critical variables of this hardening are hemodynamics effects and considered as the reason of plaque due to which normal circulation of blood is interrupted. Different arterial diseases such as stenosis or an aneurysm can alter the blood flow characteristics in an artery. The growth of atherosclerotic plaques that lump into the lumen is the known reason of tapering of stenosed blood vessels. Development of stenosis in an artery leads to severe situations such as the enhanced resistance and reduction of blood flow to the different organs of the body, which further can cause severe arterial disorders inside the human body.

Considering the need of life science problems in the past time, a numerous number of mathematical models have
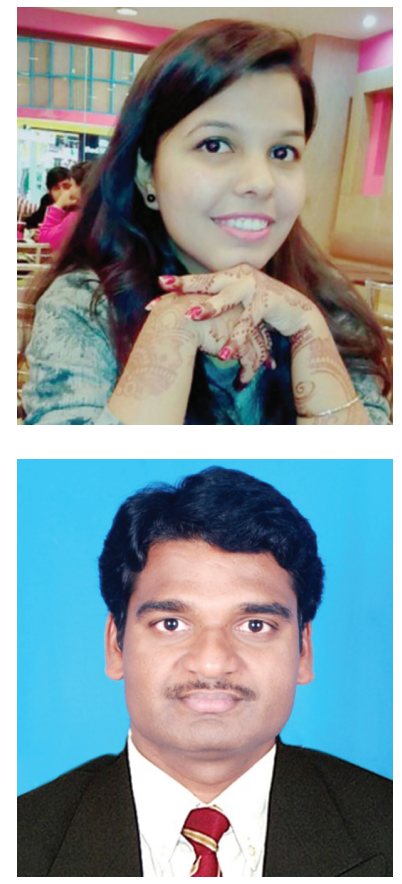

Jayati Tripathi was born in Uttar Pradesh, India. She is currently working as a Senior Research Fellow (SRF) in the Department of Mathematics, Motilal Nehru National Institute of Technology Allahabad, India. Her research interests are directed towards Biofluid Dynamics, Heat and Mass Transfer, Nanofluids and Bio-fluids Flow Modelling. During her post-graduation and research, she has developed some numerical codes for finite difference method to solve highly complex non-linear problems.

B. Vasu was born in Andhra Pradesh, India. He obtained his Doctoral degree in Fluid Dynamics. He is presently working as Assistant Professor in the Department of Mathematics, Motilal Nehru National Institute of Technology Allahabad, India. His primary research interests are directed towards Numerical Analysis, Fluid Dynamics, Heat and Mass Transfer, Nanofluids and Bio-fluids Flow Modelling, Newtonian and non-Newtonian Boundary Layer Flows. During his teaching and research, he has been developed some numerical codes for implicit Keller-box numerical programs to nonlinear fluid dynamics and thermal sciences problems. Apart from his research skills, he has authored or co-authored several journal papers in good impact factor international journals and 3 books/book chapter. In addition to his research skills, he has developed presentation, team working and organization skills. He has been awarded UGC Research Award for 2014-16 by University Grants Commission, India. 


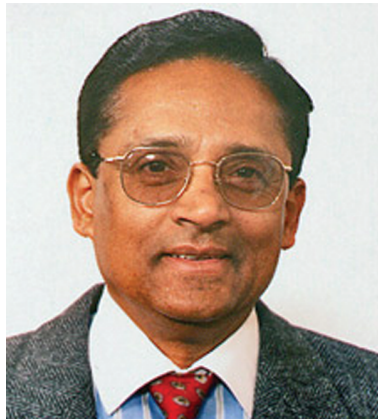

Rama Subba Reddy Gorla is presently working as Professor of Aerospace Engineering in the Department of Aeronautics and Astronautics, Air Force Institute of Technology, USA. Prior to this, he was Fenn Distinguished Research Professor in the Department of Mechanical Engineering at Cleveland State University. He received the Ph.D. degree in Mechanical Engineering from the University of Toledo in 1972. His primary research areas are combustion, heat transfer and fluid dynamics. He was involved in the testing and development of a three-dimensional Navier Stokes Computational Code for Wright Patterson Air Force Base. He worked as a turbomachinery design engineer at Teledyne Continental Motors Turbine Engines (TCM-TE) in Toledo, Ohio and as a design engineer of the aerothermodynamics of rotating machinery at Chrysler Corporation in Highland Park, Michigan. He completed a research program funded by NASA Lewis Research Center in Turbine Heat Transfer. Dr. Gorla has published over 550 technical papers in refereed journals and contributed several book chapters in Encyclopedia of Fluid Mechanics. NASA, AFOSR and local industry have sponsored his research. He co-authored text books on Advanced Differential Equations published by Studera Press in 2016 and Turbomachinery published by Marcel \& Dekker Company in 2003. He is the recipient of two Distinguished Faculty awards from Cleveland State University, the first for research in 1999 and the second for teaching in 2004. He was given the Teaching Excellence Award from the Northeast Ohio Council on Higher Education in 2004. He received the Distinguished Technical Educator Award from the Cleveland Technical Societies Council in May 2006. He serves on the editorial board of several journals.

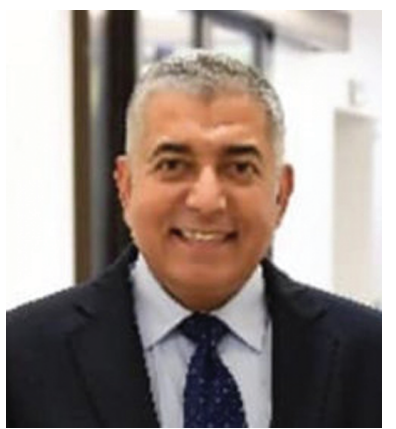

Ali J. Chamkha is a Distinguished Professor of Mechanical Engineering and Dean of Engineering at Kuwait College of Science and Technology. He earned his Ph.D. in Mechanical Engineering from Tennessee Technological University, USA, in 1989. His research interests include multiphase fluid-particle dynamics, nanofluids dynamics, fluid flow in porous media, heat and mass transfer, magnetohydrodynamics and fluid-particle separation. He is currently the Editor-in-Chief for the Journal of Nanofluids and has served as an Editor, Associate Editor or a member of the editorial board for many journals such as ASME Journal of Thermal Science and Engineering Applications, ASME Journal of Nuclear Engineering and Radiation Science, International Journal of Numerical Method for Heat and Fluid Flow, Journal of Thermal Analysis and Calorimetry, Thermal Science journal, Scientia Iranica, Special Topics \& Reviews in Porous Media, Journal of Porous Media, Journal of Thermal Engineering, Recent Patents on Mechanical Engineering, Journal of Applied Fluid Mechanics, International Journal of Fluids and Thermal Sciences, Journal of Heat and Mass Transfer Research, International Journal for Microscale and Nanoscale Thermal and Fluid Transport Phenomena, International Journal of Industrial Mathematics and many others. He has authored and co-authored over 850 publications in archival international journals and conferences. Professor Chamkha was included in the World's Top 2\% Scientists 2020 list (by Stanford University) with a Global Rank \#21 out of a total of 92,645 and Rank \#1 at the Arab World level in Mechanical Engineering and Transports category with a composite score of 4.41196994845 . His score puts me in the top $0.02266717 \%$ worldwide.

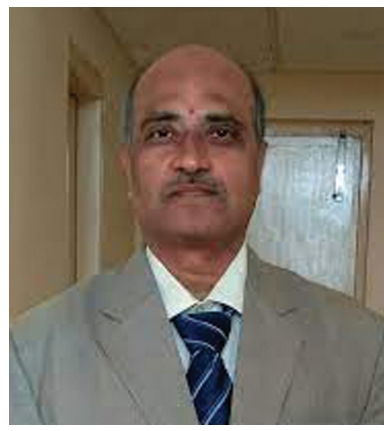

P. V. S. N. Murthy is presently working as Professor in the Department of Mathematics, Indian Institute of Technology Kharagpur, and West Bengal, India. He obtained his Doctoral degree in Fluid mechanics from Indian Institute of Technology, Kanpur. His primary research interests are directed towards Bio-fluid mechanics, Double-diffusion convective instability, convective Transport in porous media. He holds Member, SPARC TEAM, Ministry of Education, Government of India; Local Institute Coordinator, SPARC, IIT Kharagpur also Past President, Indian Society of Theoretical and Applied Mechanics (ISTAM). He has supervised many of Ph.D. students, published 122 research articles in the leading journals. 


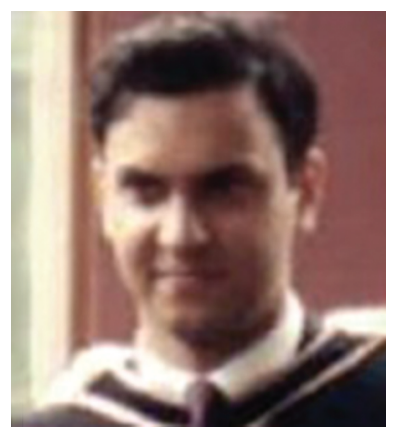

O. Anwar Bég holds the Chair in Engineering Science (Fluid Dynamics) at the Department of Aeronautical and Mechanical Engineering, Salford University, Manchester, UK. He leads the Multi-Physical Engineering Sciences Research Group (MPESG) and is active in many areas of engineering sciences including micropolar fluids, multi-physics, functional graded materials, biological fluid dynamics, nanoscale flows, hydrodynamic stability, Taylor dispersion, computational fluid dynamics, hybrid fuel cells, aerospace propulsion (gas turbines) and solar energy. He has supervised a number of Ph.D. students, published 540 journal papers and also a number of book chapters and books in micropolar fluid dynamics, nanofluid coating systems, electromagnetic propulsion and the history of engineering science. He has also co-edited the book "Modeling and Simulation in Engineering Sciences," published by Intech Press (2016). His heroes are A.C. Eringen, pioneer in engineering sciences and L.D. Landau, pioneer in superfluidity and superconductivity. He has been an Associate Editor of the Journal of Mechanics in Medicine and Biology since 2010. He obtained his Ph.D. in Computational Magnetohydrodynamics from Manchester University in March 1996.

been analyzed for blood flow through the arteries with or without stenosis, defining different viewpoints mentioned in arterial biomechanics area. For mostly investigations, blood vessel is considered as cylindrical pipe having uniform cross-section area everywhere. Related to this, in 1968 , Whitmore ${ }^{1}$ propounded that the arterial vessels have tendency of bifurcation at recurrent intervals and the diameter of the artery also get change with the distance. However, in understanding the blood flow phenomenon, the flow in fluctuating blood vessel is the prime reason for a large number of investigations by Manton $^{2}$ and Hall. ${ }^{3}$ As the exact reason for stenosis formation is not known, although researchers have investigated theoretically and experimentally the impact of stenosis over blood flow characteristics. Accordingly, numerous investigations have discussed the flow characteristics (like blood velocity, pressure and shear stress) to understand their role in stenosis formation and the validity of treatments. ${ }^{4-7} \mathrm{~A}$ large number of investigations have been performed to elaborate the blood flow phenomenon in arteries.

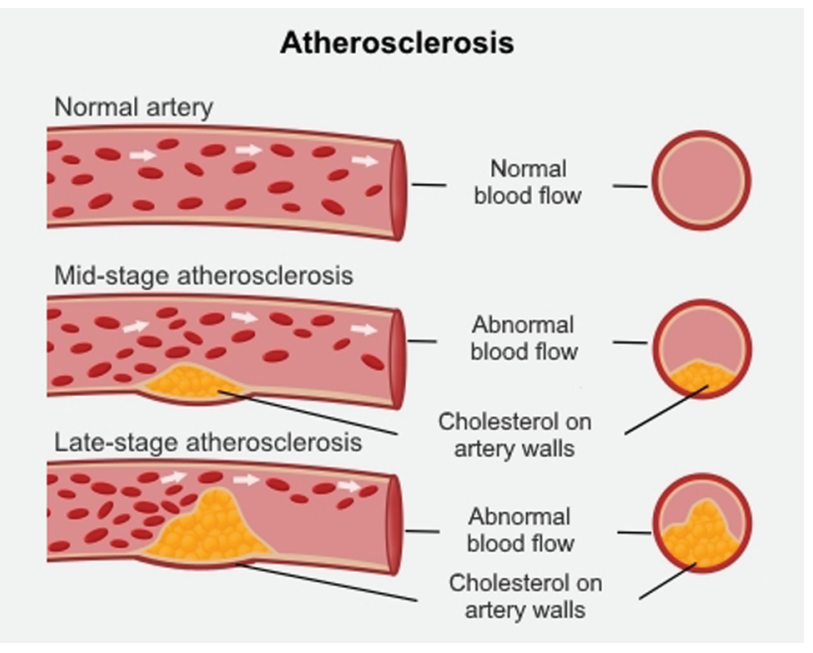

Fig. 1. Atherosclerosis. ${ }^{8}$

\subsection{Blood Flow in Arterial System}

Human blood is a heterogeneous multiphase suspension of blood cells (erythrocytes, leukocytes, platelets) in plasma, which is about $55 \%$ of total blood volume and is composed of mostly water, dissipated proteins, mineral ions, clotting factors, hormones and blood cells, which is represented by Figure 2. Blood has a complex macroscopic behavior due to the properties of the constituents and the composition of blood. It has been pointed out that the nature of plasma is Newtonian fluid; ${ }^{9}$ however, whole blood exhibits nonNewtonian fluid characteristics. ${ }^{10}$ Blood cell and plasma characteristics are presented in Tables I and II respectively. Behaviour of blood as Newtonian or non-Newtonian fluid depends on the nature of the blood transportation process as well as on the size and shape of vessel. Blood having shear rate greater than $100 \mathrm{~s}^{-1}$ shows a Newtonian nature. For example, in large arteries, veins and in large cavities, blood exhibits Newtonian characteristics. However, for shear rate less than $100 \mathrm{~s}^{-1}$, blood present nonNewtonian nature. In general, in capillaries, arterioles and in myocardium, non-Newtonian effects can be seen.

Blood vessels are one of the important components of the circulatory system. These are mainly branched into

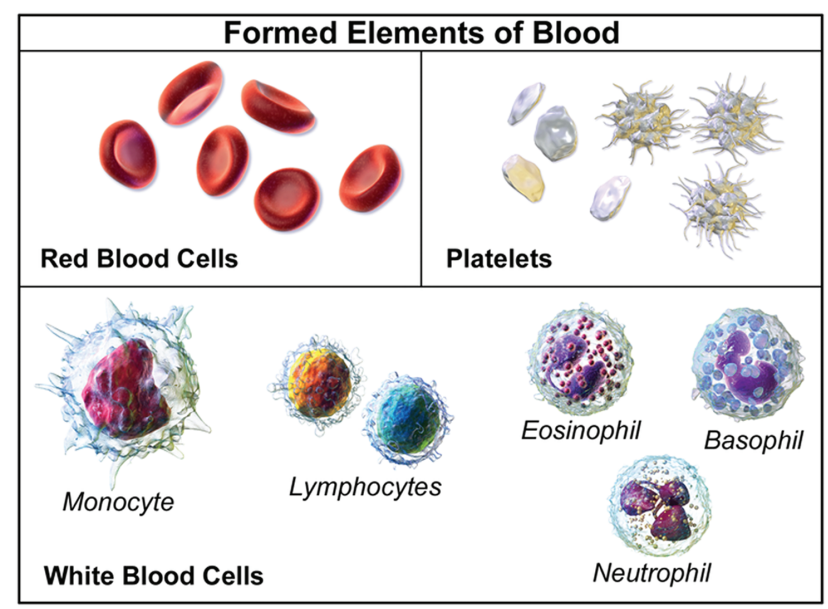

Fig. 2. Elements of blood. ${ }^{11}$ 
Table I. Blood cell components.

\begin{tabular}{lccc}
\hline Blood component & Size $(\mu \mathrm{m})$ & Per microliter & Percentage \\
\hline Erythrocytes (RBC) & $7-8$ & $4.1-5.1 \times 10^{6}$ & 97 \\
Leukocytes (WBC) $\left(4-10 \times 10^{3}\right)$ & & & \\
$\quad$ Neutrophils & $10-12$ & $62 \%$ of Leukocytes & 2 \\
Lymphocytes & $6-14$ & $30 \%$ & \\
Eosinophils & - & $2.3 \%$ & \\
Monocytes & $15-20$ & $5.3 \%$ & \\
$\quad$ Basophils & & $0.4 \%$ & \\
Platelet & 3 & $1.5-4.5 \times 10^{5}$ & 1 \\
\hline
\end{tabular}

capillaries, arteries and veins (Fig. 3), in which veins are responsible for carrying deoxygenated blood towards the heart whereas arteries are responsible for carrying oxygenated blood towards the different parts of the body. Generally, capillaries are of size about 5-10 $\mu \mathrm{m}$ in diameter and veins ranges between $1 \mathrm{~mm}$ to $1-1.5 \mathrm{~cm}$ in diameter. In the case of arteries, elastic artery diameter is always more than $1 \mathrm{~cm}$ whereas for muscular arteries, its range is 0.1-10 mm. The thermophysical properties of blood, for example, viscosity, density etc. are shown in Table III. It is seen that different parameters like temperature, age and hematocrit alter the thermophysical properties of blood.

Another critical feature of arterial blood flow is its pulsatile behavior, which was highlighted by Ling and Atabek. ${ }^{12}$ Normally, blood flow in arteries is taken as a laminar flow, but due to the development of stenosis, hardening of the arterial wall etc, interruption in the flow of blood is generated and reduces the required blood flow, which further leads to breaking down of the blood circulatory system. This makes it necessary to have detailed knowledge of blood flow in the detection of arterial diseases. ${ }^{13}$ Velocity, pressure, viscosity, fluid-structure interaction are the basic quantities and phenomenon that completely describes the blood flow phenomenon. ${ }^{14}$

Across a wide range of cardiovascular diseases, the best outcome depends on the physician's competency of injecting the drugs to a particular affected area. Despite numerous research and development for drug delivery, present-day formulations still leave the drugs incompetent in localizing en mass at affected site. These drug molecules disperse and spread randomly throughout the body, resulting in undesirable side effects and this reduces the active

Table II. Plasma characteristics.

\begin{tabular}{lcc}
\hline Plasma component & Component & Density $(\mathrm{g} / \mathrm{dl})$ \\
\hline Plasma & & \\
Water 91\% & Albumin & 4.5 \\
Protein 7\% & Immunoglobulin & 0.3 \\
& Fibrinogen & 2.5 \\
& Prothrombin & 0.015 \\
Other & & \\
Salt includes vitamin, & \\
$\quad$ lipid, sugar etc. & \\
\hline
\end{tabular}

Table III. Blood's various properties.

\begin{tabular}{lccc}
\hline Thermophysical properties & Erythrocytes & Blood & Plasma \\
\hline Density $\left(\mathrm{kg} / \mathrm{m}^{3}\right)$ & 1125 & 1060 & 1025 \\
Specific heat capacity $\left(\mathrm{J} / \mathrm{Kg}{ }^{\circ} \mathrm{C}\right)$ & - & 3750 & - \\
Thermal conductivity $(\mathrm{W} / \mathrm{mK})$ & $0.45-0.482$ & 0.492 & 0.57 \\
Viscosity $(\mathrm{cp})$ & 6 & 3 & 1.2 \\
Electrical conductivity $(\mathrm{S} / \mathrm{m})$ & - & 0.667 & 2 \\
\hline
\end{tabular}

response of proper doses. Since past few years, a advanced specialization of fluid dynamics, named nanofluid dynamics has emerged, which receives mixed applications in energy, biology and medical science fields.

In comparison with pure fluids, Nanofluids which are the suspensions of dissimilar nanoparticles in base fluid, may demonstrate contrasting thermal characteristics. As an example, various experiments have been conducted with nanofluids, which result that thermal conductivities of these fluids are remarkably increased and hence nanofluids are beneficial for micro-scale cooling applications.

A significant distinct utilization of nanofluid can be seen in modern medicine field. In this area, for example, nano-drugs are embodied in micro-channels for controlled delivery with bio-MEMS (micro electro-mechanical system). For this purpose, nanoparticle-based drug delivery has immense potential for therapeutics having minimal side effects and optimizing specific targeted delivery. In spite of the potential of increasing a drug's propensity to accumulate at a targeted sited, the platform also faces a complex series of biological barriers that limit sitespecific bioavailability, preventing achievement of proper

\section{Blood vessels types}

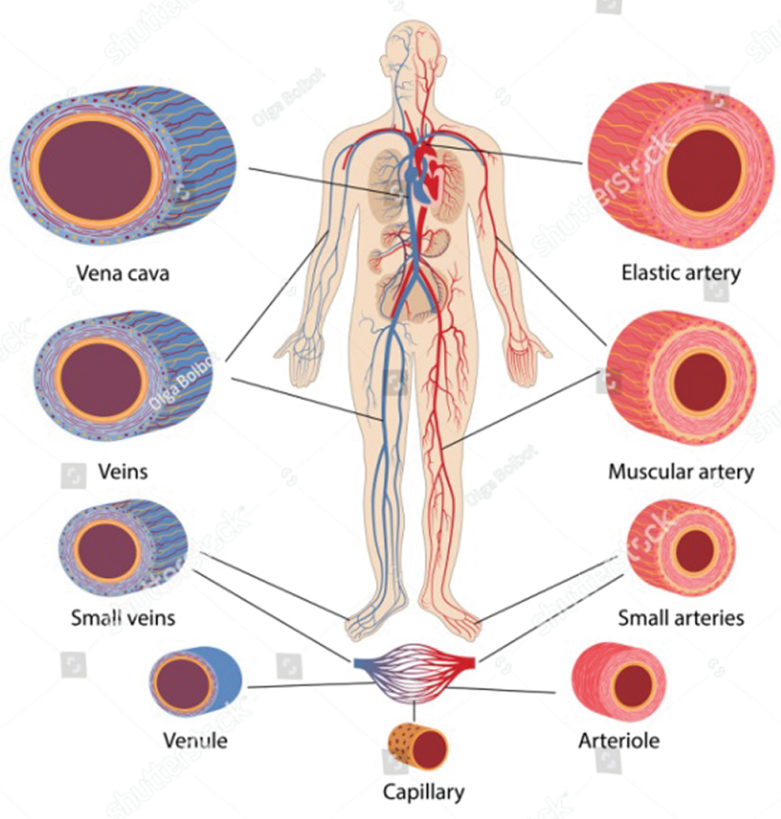

Fig. 3. The major subsystem of blood vessels. ${ }^{39}$ 


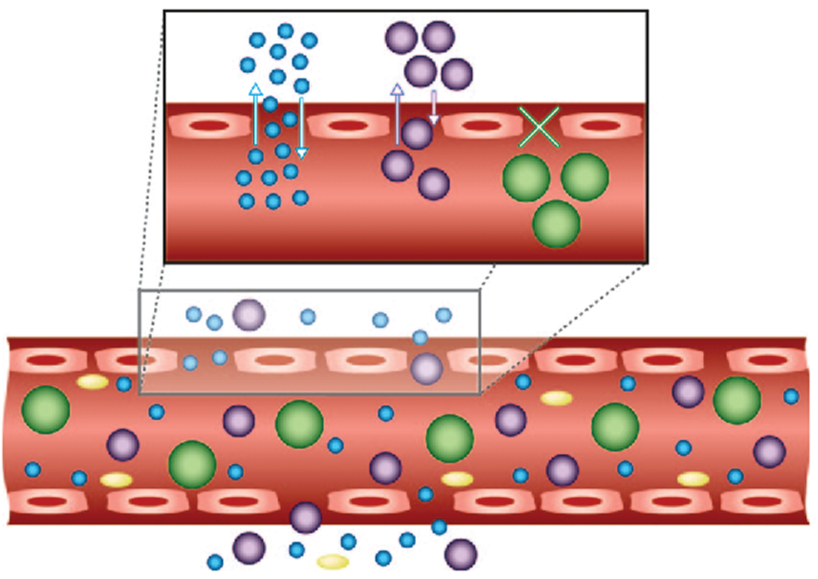

Fig. 4. Nanoparticle flow, margination and adhesive properties in blood vessels depending on geometry and particle size. Reprinted with permission from [15], O. C. Farokhzad and R. Langer, ACS Nano 3, 16 (2009). Copyright@American Chemical Society.

therapeutic outcomes. For treatment and diagnosis purpose or in drug delivery areas, nanoparticles like copper have been extensively purposed.

The delivery of the nanoparticles in the artery is strongly dependent on the size, shape and material of nanoparticles. Conventional nanoparticles like polymer nanoparticles and liposomes, having spherical geometry and size $10-100 \mathrm{~nm}$ in diameter, are designed particularly for the arterial delivery. This is due to the fact that small spherical particles, such as liposomes, are found in a particular region of the blood vessel, called as the cell-free layer, which is a direct result of the tendency of red blood cells to accumulate selectively within the core of a vessel (Fig. 4). Many investigations ${ }^{16,17}$ have shown that nanoparticles having spherical shapes show minimum lateral drift and are less likely to migrate to vessel walls. According to the hemorheological behavior of nanoparticles, the presence of external force, like the magnetic field, improves specific target delivery.

\subsection{Models for Blood Flow}

As we have discussed above, whole blood has Newtonian and non-Newtonian fluid characteristics, under certain restrictions. It is concluded that in small vessels having diameter not more than $0.5 \mathrm{~mm}$ and having low shear rate, non-Newtonian character of blood has always been found while it exhibits a Newtonian fluid nature in large vessels where shear rate is high. There are several generalized non- Newtonian models (Power-law, Carreau-Yasuda, Herschel-Bulkley etc. $)^{18}$ and viscoelastic fluid models ${ }^{19}$ which have been used to simulate the non-Newtonian behavior of blood. Further, numerous investigation have confirmed that hemodynamics plays an important role in atherosclerotic lesions due to which normal circulation of blood is disrupted. Morgan and Young ${ }^{20}$ investigated the pressure drop in arterial diseases. Furthermore, clinical data have stated that stenosis does not have a specific shape. ${ }^{21}$ The arterial regions having high curvatures and bifurcation are the most suitable destination inclined to plaque restriction. Tapering of the artery also affects the flow behavior in a very particular manner. A large number of investigations have been accomplished for the flow characteristics in tapered and non-tapered arteries. ${ }^{190-193}$ Further, some important blood flow models with their constitutive equation are summarized below:

- Power-law Fluid: The commonly used viscosity model representing the non-Newtonian nature of blood is the power law fluid ${ }^{18,22}$ which has considerable practical significance. The constitutive equation used by many researchers $^{23,24}$ is

$$
\tau=\eta_{o}\left(\frac{\partial v}{\partial y}\right)^{(m-1)}
$$

where $\tau$ represents the shear stress, $(\partial v / \partial y)$ is shear rate, and $m$ is power index. This power index is mainly responsible for the behavior of flow, as $m<1$ denotes the shearthinning fluid, $m>1$ is for shear-thickening fluid and for $m=1$, it behaves as Newtonian fluid.

- Carreau-Yasuda Fluid: The only limitation of the power-law viscosity model is that it is not able to calculate viscosity for large or small shear rates. So to overcome the limitation, Carreau-Yasuda non-Newtonian fluid ${ }^{25}$ is suggested, for calculating the viscosity for both shear rates. The constitutive equation for this model is:

$$
\tau=\left[\eta_{\infty}+\left(\eta_{o}-\eta_{\infty}\right)\left(1+(\lambda \dot{\gamma})^{2}\right)^{(n-1) / 2}\right] \dot{\gamma}
$$

Here the physical parameters given in above equation are defined as, $\tau$-stress tensor, $\eta_{o}$-zero shear rate viscosity, $\eta_{\infty}$-infinite shear rate viscosity, $n$ - power index and $\dot{\gamma}$ is given by:

$$
\dot{\gamma}=\sqrt{\frac{1}{2} \sum_{i} \sum_{j} \dot{\gamma}_{i j} \dot{\gamma}_{j i}}
$$

For many cases, when $\left(\eta_{\infty}\right)$ is much less than $\left(\eta_{o}\right)$, then we take $\eta_{\infty}=0$, and the above constitutive equation will reduce to:

$$
\tau=\eta_{o}\left(1+(\lambda \dot{\gamma})^{2}\right)^{(n-1 / 2)} \dot{\gamma}
$$

- Casson Fluid: This non-Newtonian model was first proposed by Casson in $1959^{26}$ to analyze the rheological behavior of inks. The important property of this fluid is that if yield stress is much lower than wall stress, it behaves as viscous fluid. For yield stress $p_{y}$ of fluid and dynamic viscosity $\mu_{B}$, the constitutive equation of Casson 
fluid is:

$$
\tau=2 \begin{cases}\left(\mu_{B}+\frac{p_{y}}{\sqrt{2 \pi}}\right) e_{i j}, & \pi>\pi_{c} \\ \left.\mu_{B}+\frac{p_{y}}{\sqrt{2 \pi_{c}}}\right) e_{i j}, & \pi<\pi_{c}\end{cases}
$$

where $e_{i j}$ is $(i, j)$ th component of deformation rate and $\pi=e_{i j} e_{i j}$ is product of components of deformation rate with itself and $\pi_{c}$ is the critical value for non-Newtonian model. Casson fluid exhibits shear thinning behavior if yield stress $\left(p_{y}\right)$ is less than shear stress and behave as a solid if shear stress is greater than yield stress $\left(p_{y}\right)$.

- Sisko Model: Sisko model is another generalized nonNewtonian model $^{27}$ whose rheological equation is given as:

$$
\bar{\tau}=-\left[a_{1}+b_{1}\left|\sqrt{\frac{1}{2}(\bar{\Delta}: \bar{\Delta})}\right|^{(m-1)}\right] \bar{\Delta}
$$

where $\bar{\Delta}$ and $\bar{\tau}$ are the rate of deformation tensor and stress tensor. $a_{1}, b_{1}$ and $m$ are different material constants for various fluids.

- Herschel-Bulkley Model: This model was first mentioned by Herschel and Bulkley in $1926 .{ }^{28}$ This fluid model characterizes the relationship between three parameters, the flow index $n$, yield shear stress $\tau_{o}$ and the consistency $k$, which is defined by:

$$
\tau=\tau_{o}+k \dot{\gamma}^{n}
$$

The effective viscosity representing the generalized Newtonian fluid is written as: ${ }^{29}$

$$
\mu_{e f f}= \begin{cases}k \dot{\gamma}_{o}^{n-1}+\tau_{o} \dot{\gamma}_{o}^{-1}, & |\dot{\gamma}| \leq \dot{\gamma}_{o} \\ k|\dot{\gamma}|^{n-1}+\tau_{o}|\dot{\gamma}|^{-1}, & |\dot{\gamma}| \geq \dot{\gamma}_{o}\end{cases}
$$

\section{NANOFLUIDS: RECENT RESEARCH, DEVELOPMENT AND APPLICATIONS}

\subsection{Nanofluids}

Conventional fluids in industrial applications exhibits excellent lubrication properties but their poor thermal properties restrain uses. Nowadays, many researchers have been endeavored to increase heat transfer rates of conventional fluids. Experimentally it was found that the addition of small-sized solid particles in the base fluid can enhance the thermophysical properties. In 1995, Choi and Eastman $^{30}$ coined a new term, "nanofluid," which is a colloidal suspension of nanometer-sized particles (1-100 nm) in a base fluid. These nanoparticles can be oxide, carbide, metallic, non-metallic, carbonic, hybrid and even other liquid droplets. The base fluid includes water, mineral oil, ethylene glycol or refrigerants. Some researchers have identifled that the inclusion of nanoparticles in base fluid increases the thermal conductivity by remarkable degrees. ${ }^{31-37}$ These particles are also synthetic materials in some applications related to bio-medicine because of the unique way of they interact with matter. ${ }^{38}$ Figure 5 represents the various applications of nanofluids.

Saidur et al. ${ }^{40}$ resulted that enhancement in volumetric particle fraction, also increased the thermal conductivity. Some experiments have shown that enhancement of viscosity increases the thermal conductivity but a little fall is observed in pressure. ${ }^{41-43}$ Tiwari et al. ${ }^{44}$ and Kumar et al..$^{45}$ noted that viscosity and density of fluid increased by the increment of nanoparticle volume concentration, which in result modified the pressure drop and hence, enhances the pumping power. Babu et al. ${ }^{46}$ studied the effects of thermal radiation and heat source on non-Newtonian nanofluid flow over a stretching sheet considering the magnetohydrodynamics. The relation between the increments of shear viscosity with the nanoparticle concentration is presented by Ref. [47]. However, the effect of Reynolds number on pressure drop has also been studied. It is verified by a few researchers ${ }^{48-51}$ that enhancement in Reynolds number also increases the pressure drop.

\subsubsection{Thermophysical Properties of Nanofluids}

On comparing with base fluids, nanofluids have completely different thermophysical properties such as density, thermal conductivity, viscosity, and specific heat capacity. To distinguish between properties of fabricated nanofluid and base fluid, we use the term "effective" to denote the thermophysical properties of nanofluid.

- Thermal Conductivity: Hamilton and $\mathrm{Crosser}^{53}$ presented a thermal conductivity model of solid-liquid

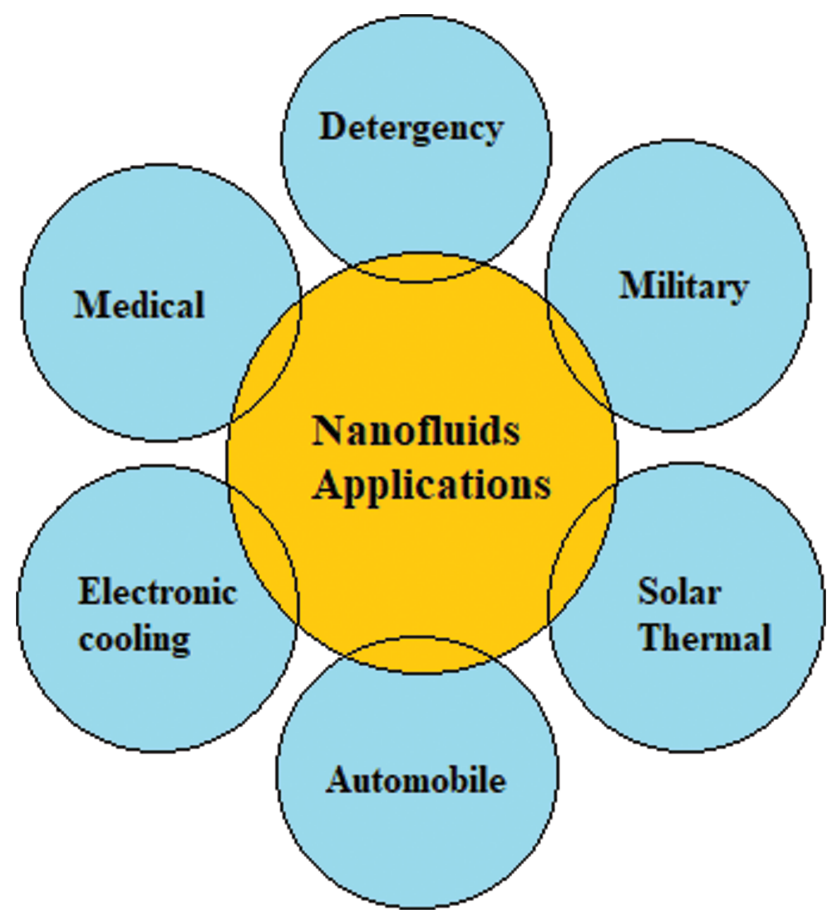

Fig. 5. Applications of nanofluids. 
mixtures of non-spherical particles, which is given as:

$$
\frac{k_{n f}}{k_{f}}=\frac{k_{p}+\left(n_{1}-1\right) k_{f}-\left(n_{1}-1\right) \phi_{1}\left(k_{f}-k_{p}\right)}{k_{p}+\left(n_{1}-1\right) k_{f}+\phi_{1}\left(k_{f}-k_{p}\right)}
$$

where $k_{p}$ and $k_{f}$ are nanoparticles and base fluid's thermal conductivity, respectively. $n_{1}$ is empirical shape factor, calculated as $n_{1}=3 / \gamma$ in which $\gamma$ shows particle sphericity. For spherical particles, $\gamma$ is 1 and 0.5 for cylindrical particles. Another model for thermal conductivity is also proposed by Maxwell ${ }^{54}$ and is found to be a special case of Hamilton and Crosser's model:

$$
\frac{k_{n f}}{k_{f}}=\frac{k_{p}+2 k_{f}-2 \phi_{1}\left(k_{f}-k_{p}\right)}{k_{p}+2 k_{f}+\phi_{1}\left(k_{f}-k_{p}\right)}
$$

- Viscosity: For the effective viscosity of nanofluid, many models have been suggested by researchers considering the nanoparticle suspension in the base fluid. The first model was suggested by Einstein $^{55}$ in 1906 using the phenomenological hydrodynamic equations. The derived equation is:

$$
\mu_{n f}=(1+2.5 \phi) \mu_{f}
$$

As the model given by Einstein is restricted to spherical particles only, some other models also have been proposed by many researchers for non-spherical particles. A very significant model was proposed by Brinkman ${ }^{56}$ in 1952 , which provides a relation between base fluid viscosity, nanoparticle concentration and the effective viscosity of nanofluid as-

$$
\mu_{n f}=\frac{\mu_{f}}{(1-\phi)^{2.5}}
$$

where $\mu_{f}$ denotes the base fluid viscosity.

- Density: With the help of the properties of both base fluid and nanoparticles, the effective density of nanofluid is numerically calculated ${ }^{52}$ as:

$$
\rho_{n f}=(1-\phi) \rho_{f}+\phi \rho_{s}
$$

where $\rho_{f}$ and $\rho_{s}$ density of the base fluid and nanoparticle respectively and $\phi$ is nanoparticle volume fraction.

- Specific Heat Capacity: The effective heat capacity can be calculated using the following equation as reported in Refs. [52, 57] as:

$$
\left(C_{p}\right)_{n f}=(1-\phi)\left(C_{p}\right)_{f}+\phi\left(C_{p}\right)_{s}
$$

Some other approaches have also been suggested regarding heat capacity concept ${ }^{58,59}$ as

$$
\left(\rho C_{p}\right)_{n f}=(1-\phi)\left(\rho C_{p}\right)_{f}+\phi\left(\rho C_{p}\right)_{s}
$$

These two formulations may, of course, lead to different results for specific heat. Due to the lack of experimental data, both formulations are considered equivalent in estimating nanofluid specific heat capacity. ${ }^{60}$

The idea of nanofluid flow has been further developed by suspending dissimilar combinations of different nanoparticles in conventional (base) fluids, which produces hybrid nanofluids.

\subsection{Hybrid Nanofluids}

Makishima $^{61}$ suggested suspensions of two or more metals in base fluid to provide a homogenous phase, entitled as hybrid nanofluid. With comparison to unitary nanofluid, hybrid nanofluids exhibited even more promising enhancement in thermophysical properties and heat transfer characteristics. Hayat and Nadeem ${ }^{62}$ performed a numerical study for the heat transfer rate in $\mathrm{Ag}-\mathrm{CuO} /$ water hybrid nanofluid in the presence of chemical reaction, thermal radiation and heat generation for steady flow and found that hybrid nanofluid possessed a higher heat transfer rate in comparison to unitary nanofluid.

Selimefendigil and Öztop ${ }^{63}$ performed a threedimensional numerical simulation in a cubic enclosure with two rotating cylinders for $\mathrm{TiO}_{2}, \mathrm{Al}_{2} \mathrm{O}_{3}$ and $\mathrm{Cu}$ nanoparticles. They observed that nanofluid containing $\mathrm{Cu}$ nanoparticles exhibited the highest heat transfer rate. Madhesh and Kalaiselvam ${ }^{64}$ investigated the heat transfer rate and rheological behavior of hybrid nanocomposite of $\mathrm{Cu}$ $\mathrm{TiO}_{2}$ having a particle concentration from 0.1 to 1 (vol\%) in water base fluid. The experimental study showed that up to 0.7 (vol\%) Nusselt number increased but as particle concentration exceeded this value, a decline was noticed. A hybrid nanofluid made of sand/encapsulated paraffin wax in propylene glycol/water mixture was studied by Manikandan and Rajan ${ }^{65}$ to observe the thermal conductivity and specific heat of the fluid. An enhancement of $9 \%$ in thermal conductivity and reduction of $18 \%$ in viscosity was found for nanoparticle concentration of $1 \mathrm{vol} \%$.

\subsubsection{Thermophysical Properties of Hybrid Nanofluids}

As we know the thermophysical properties are very significant since they allow us to take into account performance with better accuracy. A major portion of literature indicates that thermal conductivity and viscosity are dependent on temperature and concentration, while the heat transfer characteristics are dependent on preparation.

- Density: The density of the hybrid nanofluid strongly influences the stability, Reynolds number and other heat transferring properties. To calculate the density of hybrid nanofluid $\rho_{\text {hnf }}$, first consider for base fluid and onenanoparticle:

$$
\rho_{n f}=\left(1-\phi_{1}\right) \rho_{f}+\phi_{1} \rho_{S_{1}}
$$

where $\rho_{n f}$ denotes a density of unitary nanofluid. Now consider for unitary nanofluid and a second nanoparticle:

$$
\rho_{\text {hnf }}=\left(1-\phi_{2}\right) \rho_{n f}+\phi_{2} \rho_{S_{2}}
$$

Using the value of $\rho_{n f}, \rho_{h n f}$ is given as:

$$
\rho_{\text {hnf }}=\left(1-\phi_{2}\right)\left[\left(1-\phi_{1}\right) \rho_{f}+\phi_{1} \rho_{S_{1}}\right]+\phi_{2} \rho_{S_{2}}
$$

Here $\rho_{f}, \rho_{S_{1}}$ and $\rho_{S_{2}}$ stand for a density of the base fluid, density of first nanoparticle and second nanoparticle, respectively. Moreover, $\phi_{1}$ and $\phi_{2}$ are nanoparticle volume fraction for particle 1 and 2 . 
- Thermal Conductivity: Thermal conductivity is a truly complex and important property of a material, which depends on important factors such as:

- Base fluid

- Particle shape

- Nanoparticle concentration

- Particle size

- Temperature

For deriving the thermal conductivity of hybrid nanofluid $k_{h n f}$, first consider the base fluid and one nanoparticle to find the thermal conductivity of unitary nanofluid $k_{n f}$ :

$$
\frac{k_{n f}}{k_{f}}=\frac{k_{S_{1}}+(n-1) k_{f}-(n-1) \phi_{1}\left(k_{f}-k_{S_{1}}\right)}{k_{S_{1}}+(n-1) k_{f}+\phi_{1}\left(k_{f}-k_{S_{1}}\right)}
$$

Hence for unitary nanofluid and a second nanoparticle

$$
\frac{k_{h n f}}{k_{n f}}=\frac{k_{S_{2}}+(n-1) k_{n f}-(n-1) \phi_{2}\left(k_{n f}-k_{S_{2}}\right)}{k_{S_{2}}+(n-1) k_{n f}+\phi_{2}\left(k_{n f}-k_{S_{2}}\right)}
$$

Where $k_{n f}$ is given in the above equation. Here $k_{f}, k_{S 1}$ and $k_{S 2}$ denote the thermal conductivity of fluid, first nanoparticle and second nanoparticle, respectively.

- Viscosity: Viscosity of the hybrid nanofluid is a key flow property and the variation in viscosity also influences factors like convective heat transfer and pressure drop directly. Viscosity of unitary nanofluid $\mu_{n f}$ for base fluid and 1-nanoparticle is given as

$$
\mu_{n f}=\frac{\mu_{f}}{\left(1-\phi_{1}\right)^{2.5}}
$$

Now considering the nanofluid and second nanoparticle, the hybrid viscosity $\mu_{\text {hnf }}$ is-

$$
\mu_{\text {hnf }}=\frac{\mu_{n f}}{\left(1-\phi_{2}\right)^{2.5}}
$$

Substituting the value of $\mu_{n f}$, we will get the $\mu_{\text {hnf }}$ as:

$$
\mu_{\text {hnf }}=\frac{\mu_{f}}{\left(1-\phi_{1}\right)^{2.5}\left(1-\phi_{2}\right)^{2.5}}
$$

In which, $\mu_{f}$ is the viscosity of base fluid.

- Specific Heat Capacity: To calculate the specific heat capacity of a hybrid nanofluid $\left(\rho C_{p}\right)_{n f}$, first consider for base fluid and one-nanoparticle:

$$
\left(\rho C_{p}\right)_{n f}=\left(1-\phi_{1}\right)\left(\rho C_{p}\right)_{f}+\phi_{1}\left(\rho C_{p}\right)_{S_{1}}
$$

where $\left(\rho C_{p}\right)_{n f}$ denotes the specific heat capacity of unitary nanofluid. Now consider for nanofluid and a second nanoparticle:

$$
\left(\rho C_{p}\right)_{h n f}=\left(1-\phi_{2}\right)\left(\rho C_{p}\right)_{n f}+\phi_{2}\left(\rho C_{p}\right)_{S_{2}}
$$

Implementing the value of $\left(\rho C_{p}\right)_{n f},\left(\rho C_{p}\right)_{h n f}$ is given as:

$$
\begin{aligned}
\left(\rho C_{p}\right)_{h n f}= & \left(1-\phi_{2}\right)\left[\left(1-\phi_{1}\right)\left(\rho C_{p}\right)_{f}+\phi_{1}\left(\rho C_{p}\right)_{S_{1}}\right] \\
& +\phi_{2}\left(\rho C_{p}\right)_{S_{2}}
\end{aligned}
$$

Here $\left(\rho C_{p}\right)_{f},\left(\rho C_{p}\right)_{S_{1}}$ and $\left(\rho C_{p}\right)_{S_{2}}$ stands for specific heat capacity of base fluid, first nanoparticle and second nanoparticle respectively.

\subsection{Physical Models}

In this section, the essential physico-mathematical models are presented, which are used to simulate the nanofluid flow and heat transfer characteristics. Figure 6 illustrates the various physical models with their further classification. The governing (transport) equations for conventional fluids i.e., the continuity, the momentum equations and the energy equation are presented for calculating velocity, temperature and pressure field due to the motion.

- Transport Equations for Conventional Fluids: Mahian et al. ${ }^{66}$ presented a robust formulation of nanofluid flows. With the help of that article, the transport equations are written below for steady, incompressible and Newtonian flow of a conventional fluid having density $\rho_{f}$, viscosity $\mu_{f}$ and thermal conductivity $k_{f}$. The conservation of mass is:

$$
\nabla \cdot\left(\rho_{f} \vec{V}\right)=0
$$

The momentum equation is as:

$$
\begin{aligned}
\rho_{f}(\vec{V} \cdot \nabla) \vec{V}= & -\nabla p+\nabla \cdot\left[\mu_{f}\left(\nabla \vec{V}+\nabla \vec{V}^{T}\right)\right] \\
& +\nabla \cdot[\lambda(\nabla \cdot \vec{V}) I]+F
\end{aligned}
$$

The parameter $\lambda$ is the second coefficient of viscosity due to viscous effects and usually it is taken as negligible. $\rho_{f}(\vec{V} \cdot \nabla) \vec{V}$ is the convective term, $\nabla \cdot\left[\mu_{f}\left(\nabla \vec{V}+\nabla \vec{V}^{T}\right)\right]$ is the viscous diffusion term and $F$ is the summation of external body forces.

For the case of incompressible flow where viscosity and density are constant, this equation can be written as:

$$
\rho_{f}(\vec{V} \cdot \nabla) \vec{V}=-\nabla p+\mu_{f} \nabla^{2} \vec{V}+F
$$

The energy equation is presented as:

$$
\nabla \cdot\left(\rho_{f} C_{p, f} \vec{V} T\right)=\nabla \cdot\left(k_{f} \nabla T\right)+\phi
$$

In this equation, $\nabla \cdot\left(\rho_{f} C_{p, f} \vec{V} T\right)$ denotes the thermal convection, $\nabla \cdot\left(k_{f} \nabla T\right)$ is heat conduction and $\phi$ is the viscous dissipation function, which is given as:

$$
\begin{aligned}
\phi= & \mu_{f}\left(2\left[\left(\frac{\partial u}{\partial x}\right)^{2}+\left(\frac{\partial v}{\partial y}\right)^{2}+\left(\frac{\partial w}{\partial z}\right)^{2}\right]+\left(\frac{\partial v}{\partial x}+\frac{\partial u}{\partial y}\right)^{2}\right. \\
& \left.+\left(\frac{\partial w}{\partial y}+\frac{\partial v}{\partial z}\right)^{2}+\left(\frac{\partial u}{\partial z}+\frac{\partial w}{\partial x}\right)^{2}\right)+\lambda(\nabla \cdot \vec{V})^{2}
\end{aligned}
$$

\subsubsection{Single-Phase Approaches}

Naturally, a nanofluid is considered as a two-phase fluid (solid-liquid); however under given conditions for numerical simulations, some relevant assumptions can be considered to model the nanofluids as a single-phase fluid. In the case of the single-phase models, the governing equations for nanofluids are solved only for a compelling liquid phase. This model can be further divided into three main components, including homogenous, nonhomogenous (Buongiorno) and thermal dispersion models. 


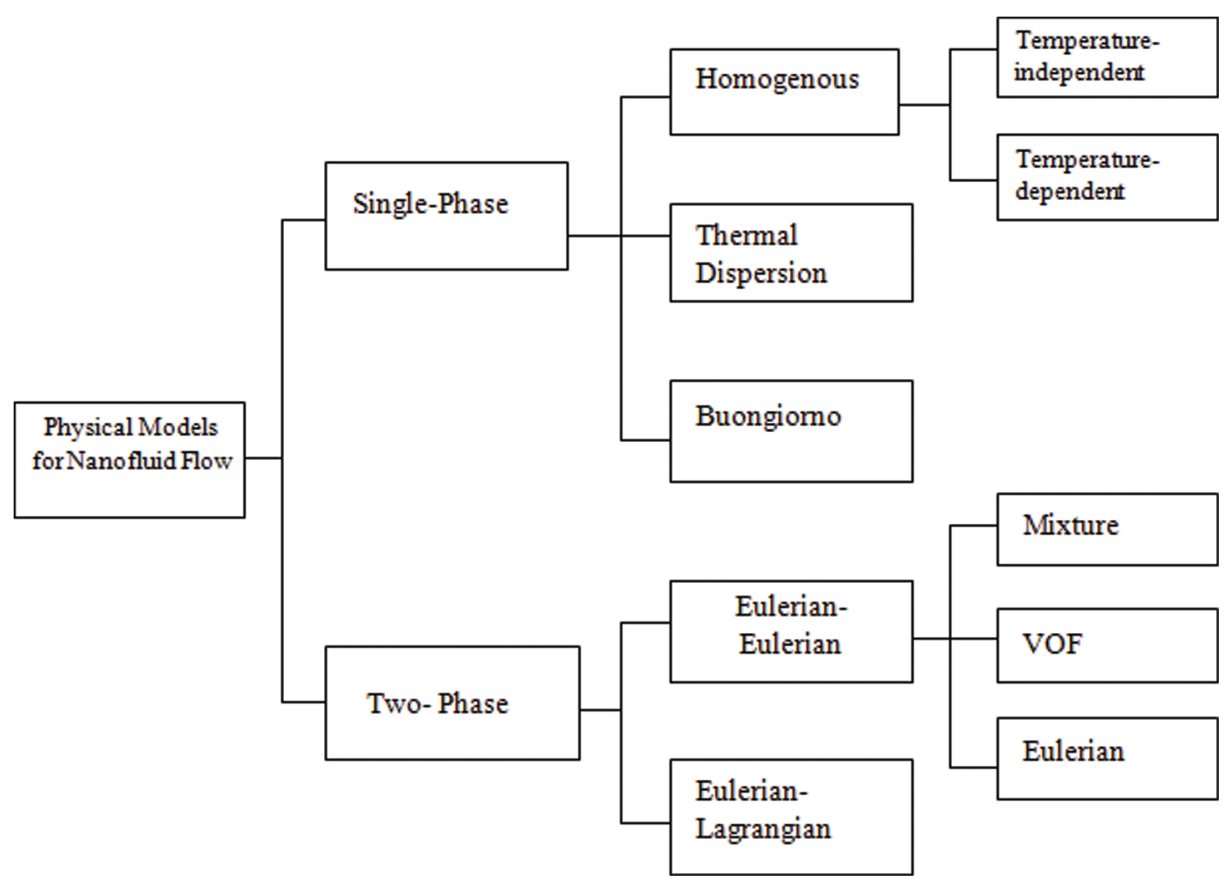

Fig. 6. Important approaches for nanofluid flow modeling.

In a square cavity, the buoyancy-driven heat transfer enhancement in nanofluids was first studied by Khanafer et al., ${ }^{67}$ using the Brinkman model $^{56}$ for viscosity and Wasp model ${ }^{68}$ for thermal conductivity. They found that at any given Grashof number, the suspended nanoparticles increases the heat transfer rate. In addition, they also observed that an increase in the nanoparticles volume fraction also increases the nanofluid heat transfer rate and the structure of fluid flow can be altered by the presence of nanoparticles in the fluid.

- Homogenous Single-phase Approach: The existence of ultrafine nanoparticles makes the mixture of base fluid and nanoparticles a multi-phase problem but it is also assumed that the nanoparticles can be easily fluidized and as a result, the nanofluid can almost be considered as a conventional single-phase (homogenous) fluid with physical properties of individual phases. This is said to be the simplest approach for modeling. The main assumptions that we consider in this model are: the slip between the nanoparticles and the base fluid is negligible and there is always a thermal and hydrodynamic equilibrium in solid and fluid phases. These assumptions imply that between the fluid and solid particles, any thermal exchange and interphase forces can be neglected. Taking negligible viscous dissipation and $\lambda=0$ for homogenous single-phase approach, ${ }^{66}$ the basic form of transport equations are presented as:

Conservation of mass:

$$
\nabla \cdot\left(\rho_{n f} \vec{V}\right)=0
$$

Conservation of momentum:

$$
\rho_{n f}(\vec{V} \cdot \nabla) \vec{V}=-\nabla P+\nabla \cdot\left[\mu_{n f}\left(\nabla \vec{V}+\nabla \vec{V}^{T}\right)\right]+F
$$

Conservation of Energy:

$$
\nabla \cdot\left(\left(\rho C_{p}\right)_{n f} \vec{V} T\right)=\nabla \cdot\left(k_{n f} \nabla T\right)+\phi
$$

In the above model, the viscosity of nanofluids is considered as a function of concentration or temperature which has been used in many studies. Choosing appropriate models for the thermophysical properties of nanofluids like thermal conductivity and viscosity is the biggest challenge of this approach. Depending on the problem complexity, these properties can be taken as time-independent or timedependent. Considering the published literature, there are only a few articles found in which both experimentally and numerically, the convective heat transfer of nanofluids has been calculated.

The numerical and experimental analysis of nanofluid laminar forced convection in double pipe and shell geometries has been presented by Akhtari et al. ${ }^{69}$ The main aim of this study was to examine the effects of nanofluid temperature, cold and hot volume flow rates and nanoparticle concentration. For modeling, they used FVM (finite volume method) commercial software Ansys-FLUENT in which un-structured quadrilateral cells were adopted. It was illustrated that by increasing the cold and hot volume flow rates, the overall heat transfer coefficient also increases and the particle concentration and nanofluid inlet temperature also rise.

Saha and Paul ${ }^{70}$ investigated the flow of water-based $\mathrm{Al}_{2} \mathrm{O}_{3}$ and $\mathrm{TiO}_{2}$ nanofluids under constant heat flux boundary conditions in a horizontal tube using the homogenous single-phase model and temperature-dependent properties. Izadi et al. ${ }^{71}$ stimulated the laminar forced convection 
of diluted $\mathrm{Al}_{2} \mathrm{O}_{3}$ and water nanofluid in an annulus. The single-phase governing equations were discretized by using the Finite Volume Method in which the first-order upwind method was employed for convective and diffusive terms and the SIMPLE algorithm employed for velocitypressure coupling.

In order to find the heat transfer coefficient and Nusselt number for the heat transfer enhancement in some simple problems where the enclosure wall has either adiabatic conditions or constant temperature, Abouali and $\mathrm{Ahmadi}^{72}$ showed that by taking nanofluid as single-phase and homogenous, there is no need to solve the governing equations. The heat transfer enhancement can be found just by calculating the ratio of nanofluid thermophysical properties to base fluid properties.

$\frac{N u_{n f}}{N u_{f}}=\left(\frac{k_{n f}}{k_{f}}\right)^{-m}\left(\frac{\mu_{n f}}{\mu_{f}}\right)^{-m}\left(\frac{C_{p, n f}}{C_{p, f}}\right)^{m}\left(\frac{\beta_{n f}}{\beta_{f}}\right)^{m}\left(\frac{\rho_{n f}}{\rho_{f}}\right)^{2 m}$

$\frac{h_{n f}}{h_{f}}=\left(\frac{k_{n f}}{k_{f}}\right)^{1-m}\left(\frac{\mu_{n f}}{\mu_{f}}\right)^{-m}\left(\frac{C_{p, n f}}{C_{p, f}}\right)^{m}\left(\frac{\beta_{n f}}{\beta_{f}}\right)^{m}\left(\frac{\rho_{n f}}{\rho_{f}}\right)^{2 m}$

Where the geometry and boundary conditions of the problem decides the value of the indicial parameter $(m)$. The literature survey indicates that the homogenous singlephase model has been used in many theoretical studies based on convective heat transfer using nanofluids. Computational efficiency and simplicity is a key point of this model. However to obtain significant results, we need to choose the most appropriate thermophysical property correlations since it is still not classified for a given situation which correlation available in the literature is the best.

- Thermal Dispersion Single-phase Approach: The chaotic movement of nanoparticles creates thermal dispersion. To handle this dispersion, Xuan and Roetzel ${ }^{73}$ first introduced the thermal dispersion single-phase approach. In this revised approach, a perturbation is introduced to both the velocity and temperature of the nanofluid by the relative motion of the nanoparticles with respect to the base fluid. Therefore, the intrinsic phase averages, considering the analogy with turbulence are given as:

$$
\begin{aligned}
& \vec{V}=\bar{V}+V^{\prime} \\
& \vec{T}=\bar{T}+T^{\prime}
\end{aligned}
$$

Where $V^{\prime}$ and $T^{\prime}$ denotes the fluctuation in temperature and velocity due to nanoparticles chaotic movement and its average value is given as $\bar{V}=\left(1 / \forall_{f}\right) \int_{\forall_{f}} \vec{V} d \forall$ and $\bar{T}=$ $\left(1 / \forall_{f}\right) \int_{\forall_{f}} \vec{T} d \forall$. Here $\forall$ is the volume of working fluid.

By neglecting the boundary surface between the nanoparticles and the fluid and substituting the values of $V$ and $T$, the energy equation will become:

$$
\nabla \cdot\left(\rho_{n f} C_{p, n f} \bar{V} \bar{T}\right)=\nabla \cdot\left(k_{n f} \nabla \bar{T}\right)-\left(\rho C_{p}\right)_{n f} \bar{V}^{\prime} \bar{T}^{\prime}
$$

The second term on the right side of the energy equation illustrates the perturbation effect of the thermal dispersion. Due to the thermal dispersion, the induced heat flux in nanofluid flow is given as:

$$
q_{d}=\left(\rho C_{p}\right)_{n f} \bar{V}^{\prime} \bar{T}^{\prime}=-k_{d} \nabla \bar{T}
$$

Where $k_{d}$ is the coefficient of dispersion thermal conductivity. The final form of the energy equation is rewritten as:

$$
\nabla \cdot\left[\left(\rho C_{p}\right)_{n f} \bar{V} \bar{T}\right]=\nabla \cdot\left[\left(k_{n f}+k_{d}\right) \nabla \bar{T}\right]
$$

Xuan and Roetzel ${ }^{73}$ formulated the dispersed thermal conductivity in nanofluids as:

$$
k_{d}=\bar{C}\left(\rho C_{p}\right)_{n f} U R
$$

Where $\bar{C}$ is a constant which can be determined by matching the experimental results and $R$ denotes the pipe radius.

Bahiraei and Hosseinalipur ${ }^{74}$ tried to determine a more accurate correlation in the radial direction for the dispersed thermal conductivity as:

$$
k_{d}=\bar{C}\left(\rho C_{p}\right)_{n f}\left(\frac{\partial v_{x}}{\partial r}\right) \phi(r) R d_{p}
$$

The above-presented relation is given for fully developed flow inside a horizontal tube; the nanoparticle distribution $\phi(r)$ here is taken as a function of radius. Many investigations have been done to simulate nanofluid flow and heat transfer with the single-phase thermal dispersion model. A study on the thermally driven two-dimensional cavity flow in $\mathrm{Cu}$ /water nanofluid using a single-phase thermal dispersion model has been carried out by Kumar et al. ${ }^{75}$ Further, to examine the $\mathrm{Al}_{2} \mathrm{O}_{3}$ and water nanofluid, Özerinç et al. ${ }^{76}$ took into account the homogenous model inside a tube having various boundary conditions. They noted that the heat transfer rate estimates with the help of this numerical method are below experimental values. Then, the thermal dispersion model was considered and examined, which however provides a good agreement with the experimental results.

To check the heat transfer enhancement in a metal foam using the dispersion model, Ameri et al. ${ }^{77}$ examined the capacity of nanofluids and they also considered the distribution of nanoparticles to be non-uniform. With the help of the control volume approach, in the entrance region of a circular tube, Mojarrad et al. ${ }^{78}$ numerically examined the heat transfer enhancement of $\mathrm{Al}_{2} \mathrm{O}_{3}$ and water-based nanofluids in addition to constant surface temperature on the walls. In the above discussed article, for radial dispersed thermal conductivity, a new correlation is suggested as:

$$
k_{d}=C_{d}\left(\rho C_{p}\right)_{n f} \frac{R \phi}{d_{p}}\left(\frac{\partial T}{\partial r}\right)
$$

- Buongiorno Model: To improve the available models, Buongiorno $^{79}$ proposed a seminal model in 2006. In his 
study, the seven slip mechanisms are developed based on the relative velocity of base fluid and nanoparticles, which include (a) Inertia (b) Diffusiophoresis (c) Brownian diffusion (d) Magnus effect (e) Gravity (f) Thermophoresis (g) Fluid drainage. The Brownian diffusion and thermophoresis slip mechanism have the most powerful impact in nanofluids. In comparison with the thermal dispersion model, this model describes the effect of the base fluid and nanoparticles relative velocity in a more significant way. Concerning the findings of Buongiorno, ${ }^{79}$ a twocomponent four-equation non-homogeneous equilibrium model for transport equations in nanofluids was established. Considering Brownian and thermophoresis effects, we can write the transport equations in the homogenous model as:

Conservation of Mass-

$$
\nabla \cdot\left(\rho_{n f} \vec{V}\right)=0
$$

Conservation of Momentum:

$$
\rho_{n f}(\vec{V} \cdot \nabla) \vec{V}=-\nabla P+\nabla \cdot\left[\mu_{n f}\left(\nabla \vec{V}+\nabla \vec{V}^{T}\right)\right]
$$

Conservation of Energy:

$$
\begin{aligned}
\nabla \cdot\left(\left(\rho C_{p}\right)_{n f} \vec{V} T\right)= & \nabla \cdot\left(k_{n f} \nabla T\right)+\left(\rho C_{p}\right)_{p} \\
& \times\left[D_{B} \nabla \phi \cdot \nabla T+D_{T} \frac{\nabla T \cdot \nabla T}{T}\right]
\end{aligned}
$$

In the above equation, Brownian diffusion and thermophoresis is represented as:

$$
\begin{gathered}
D_{B}=\frac{k_{B} T}{3 \pi \mu_{n f} d_{p}} \\
D_{T}=0.26 \frac{k_{n f}}{2 k_{n f}+k_{p}} \frac{\mu_{n f}}{\rho_{n f}} \phi
\end{gathered}
$$

Conversion of Nanoparticles:

$$
\vec{V} \cdot \nabla \phi=\nabla \cdot\left[D_{B} \nabla \phi+D_{T} \frac{\nabla T}{T}\right]
$$

Based on the literature survey, some studies have been done using the Buongiorno model to analyze the convection heat transfer of nanofluids. Vasu et al. ${ }^{80}$ applied the Buongiorno model to unsteady nanofluid flow in the forward stagnation region of a heated sphere to study the heat and mass transfer phenomenon using a nonlinear Boussinesq approximation. Vasu et al. ${ }^{81}$ used the revised Buongiorno model along an inclined plate to study the hydrodynamics, heat and mass transfer in a non-Newtonian power law fluid film suspending with nanoparticles. In further studies, Garoosi et al. ${ }^{82,83}$ carried out a numerical simulation for natural and mixed convection of water-based $\mathrm{Al}_{2} \mathrm{O}_{3}$ nanofluid in a square cavity applying Buongiorno model.

Using the Homotopy semi-numerical modeling method for non-Newtonian nanofluid external to three different geometries with variable wall temperature and nanoparticle concentration condition, Buongiorno model was used by Ray et al. ${ }^{84}$ Considering the effects of Brownian motion and thermophoresis, Vasu et al. ${ }^{85}$ conducted an entropy analysis in steady laminar thin film convection flow of a power-law fluid with nanoparticles using Buongiorno's model. Gorla et al. ${ }^{86}$ investigated the mixed convective boundary layer flow adjacent to a vertical stretching surface using the Buongiorno model for non-Newtonian nanofluid in unsteady condition. Furthermore, Gorla and $\mathrm{Vasu}^{87}$ examined the unsteady forced convective boundary boundary layer flow over a stretching sheet with the nonNewtonian nanofluid using the Buongiorno model. The Keller-box implicit finite difference method was used to solve non-linear system of equations. Vasu et al. ${ }^{88}$ considered two-dimensional non-Newtonian blood flow through a stenosed coronary artery with a suspension of nanoparticles. For the convection of nanoparticles in the blood, Buongiorno's model again was considered.

Malvandi et al. ${ }^{89}$ applied the modified two-component four-equation non-homogenous equilibrium model to study the fully developed mixed convective nanofluid flow in an annulus. Taking into account the thermophoresis and Brownian diffusion effects, Sheremet and Pop ${ }^{90}$ studied the natural convection in a square porous cavity using Buongiorno's model in the steady-state. Furthermore, for alumina and water-based nanofluid, Malvandi and Ganji ${ }^{91}$ studied the mixed convective heat transfer inside a micro channel and found that the effect of nanoparticle migration was correctly simulated with the modified Buongiorno model.

\subsubsection{Two-Phase Approaches}

Normally, nanofluids are two-phase fluid by nature, so the classical theory of two-phase fluids can be implemented for nanofluids. In this approach, the assumption that nanoparticle and base fluid as two different phases having different temperature and velocity, and have zero slip velocity between the particles and fluid, is no longer valid. ${ }^{92}$ For the stated reason as this approach deals with the movement between the fluid and nanoparticles, the results may be more realistic. The two-phase approach further divided into two models: Eulerian-Eulerian and Lagrangian-Eulerian.

- Eulerian-Eulerian Model: This model is recommendable for the mixture containing a large amount of solid particles but it is not suitable for tracking the path of suspended nanoparticles. ${ }^{93}$ This model can be further subdivided as: (a) VOF model (b) Mixture model and (c) Eulerian model.

(a) Volume of Fluid (VOF) Model: In this model, the nanoparticles concentration is tracked by solving the continuity equation for the base fluid and the velocity shared by both phases is determined by a single set of NavierStokes equations for the base fluid. In the same manner, 
the shared temperature is obtained by using a single energy equation. ${ }^{94}$ The continuity equation is represented as:

$$
\nabla \cdot\left(\phi_{p} \rho_{p} \vec{V}_{p}\right)=0
$$

Where $p$ stands for the phase. Here the summation of volume fraction of all phases will be one, $\sum_{p=1}^{n} \phi_{p}=1$. The other conservation equations (momentum and energy) will be the same as for the single-phase homogenous model. For combined convection and laminar flow, Akbari et al. ${ }^{94}$ inspected the single-phase and three available EulerianEulerian models to review their accuracy with the help of experimental data. They showed that two-phase models provides more accurate results.

Further, all the two-phase models present similar predictions of experimental data but because of the lowest computational time, the VOF model is more attractive. Similarly, considering $\mathrm{Cu}$ /water nanofluid flow Rashidi et al. ${ }^{95}$ analyzed the two-phase and single-phase approaches in a channel with wavy walls. Davarnejad and Jamshidzadeh ${ }^{96}$ also compared three individual models i.e., single-phase, mixture and VOF for turbulent heat transfer using $\mathrm{MgO} /$ water-based nanofluid and found that the two-phase model is more accurate for heat transfer prediction.

(b) Mixture Model: The mixture model is basically applicable for flows having two or more phases and each phase has a different concentration and velocity field. This model requires less computational time and $\mathrm{CPU}$ usage than some existing models and for a large group of multi-phase problems, it is more feasible. Nanoparticles are signified by the base fluid via drag and turbulence, while the base fluid is affected by nanoparticles via enhanced turbulence dissipation and reduction in mean momentum. For this model, ${ }^{97}$ the mass and the energy equations are similar to the single-phase model while in the momentum equation of the mixture model, it includes an extra term to take the effect of drift velocity between the phases. Further, for the secondary phases flow, a volume fraction equation must also be solved.

Continuity Equation:

$$
\nabla \cdot\left(\rho_{m} \vec{V}_{m}\right)=0
$$

Momentum Equation:

$$
\begin{aligned}
\rho_{m}\left(\vec{V}_{m} \cdot \nabla\right) \vec{V}_{m}= & -\nabla p+\nabla \cdot\left[\mu_{m}\left(\nabla \vec{V}_{m}+\nabla \vec{V}_{m}^{T}\right)\right] \\
& +\nabla \cdot\left(\sum_{k=1}^{n} \phi_{k} \rho_{k} \vec{V}_{D R, k} \vec{V}_{D R, k}\right)+F
\end{aligned}
$$

Energy Equation:

$$
\nabla \cdot\left(\sum_{k=1}^{n} \phi_{k} \rho_{k} C_{p, k} \vec{V}_{k} T_{k}\right)=\nabla \cdot\left(\sum_{k=1}^{n} k_{e f f} \nabla T_{k}\right)
$$

Volume fraction equation foe a secondary phase $q$ :

$$
\nabla \cdot\left(\phi_{p} \rho_{q} \vec{V}_{m}\right)=-\nabla \cdot\left(\phi_{p} \rho_{q} \vec{V}_{D R, q}\right)
$$

Where $\vec{V}_{D R, k}$ stands for the drift velocity of phase $k$. However, the mixture velocity $\vec{V}_{m}$ is given as:

$$
\vec{V}_{m}=\frac{\sum_{k=1}^{n} \phi_{k} \rho_{k} C_{p, k} \vec{V}_{k}}{\rho_{m}}
$$

From the literature survey, it has been noted that most of researchers used a mixture model for nanofluid studies because it takes less computational power and it is also relatively more accurate than any other method. Safikhani et al. ${ }^{99}$ experimented in horizontal flat tubes to find heat transfer coefficients and pressure drops using a mixture model for $\mathrm{Al}_{2} \mathrm{O}_{3}$ /water nanofluid flow. In the same way, Labib et al. ${ }^{100}$ investigated the heat transfer coefficient for the $\mathrm{Al}_{2} \mathrm{O}_{3}$-CNTs/water and $\mathrm{Al}_{2} \mathrm{O}_{3}$ /water-ethylene glycol nanofluids using a mixture model in a circular tube. Goodarzi et al. ${ }^{101}$ employed the mixture model in mixed convection in a rectangular shallow enclosure containing the $\mathrm{Cu}$ /water nanofluids.

To simulate two-phase $\mathrm{Cu} /$ water nanofluid, Emami et al. ${ }^{102}$ adopted the mixture model inside an inclined cavity with different hot-wall configurations. The mixture equations in non-dimensional form were first investigated by Siavashi and Rostami ${ }^{103}$ in a porous annulus to model non-Newtonian nanofluid. Maghsoudi and Siavashi ${ }^{104}$ evaluated the optimal pore size configuration in a porous lid-driven cavity by simulating mixed convection of nanofluid using a mixture model. Further, Moraveji and Ardehali ${ }^{105}$ compared the experimental data for four individual models (Single phase, mixture, VOF, Eulerian) in a mini channel heat sink for laminar forced convection on $\mathrm{Al}_{2} \mathrm{O}_{3}$ nanofluid and observed that taking into account both accuracy and computational speed, the mixture model is the most suitable approach.

(c) Eulerian Model: This model is said to be the most complex model because of its strong coupling between phases. The basic difference between the Mixture model and the Eulerian approach is that in the Eulerian model, we solve transport equations independently for each phase. This model is found to be most suitable for simulation of fluidized beds, particulate flow and bubbly flows and further it can also be applied in the case of nanofluid simulation. In the Eulerian model, the governing model for laminar flow is represented as: $:^{98}$

The mass conservation equation for phase $\mathrm{p}$ is:

$$
\nabla \cdot\left(\phi_{p} \rho_{p} \vec{V}_{p}\right)=0
$$

And here $\sum_{p=1}^{n} \phi_{p}=1$.

The momentum equation is expressed as:

$$
\begin{aligned}
\phi_{p} \rho_{p}\left(\vec{V}_{p} \cdot \nabla\right) \vec{V}_{p}= & -\phi_{p} \nabla p+\nabla \cdot\left[\rho_{p} \phi_{p}\left(\nabla \vec{V}_{p}+\nabla \vec{V}_{p}^{T}\right)\right] \\
& +\sum_{k=1}^{n} R_{k p}+\left(F+F_{L}+F_{w L}+F_{A}\right)_{p}
\end{aligned}
$$


where $R_{k p}$ stands for the interaction force between the particulate phase $k$ and $F, F_{L}, F_{w L}$ and $F_{A}$ denotes the body, lift, wall lubrication and virtual mass forces.

The interaction force $R_{k p}$ is given by:

$$
R_{k p}=\sum_{k=1}^{n} K_{k p}\left(\vec{V}_{k}-\vec{V}_{p}\right)
$$

The energy equation is represented as:

$$
\begin{aligned}
\nabla & \cdot\left(\phi_{p}\left(\rho C_{p}\right)_{p} \vec{V}_{p} T_{p}\right) \\
& =\nabla \cdot\left(\phi_{p} \nabla T_{p}\right)-\left[\mu_{p} \phi_{p}\left(\nabla \vec{V}_{p}+\nabla \vec{V}_{p}^{T}\right)\right]: \nabla \vec{V}_{p}+\sum_{k=1}^{n} Q_{k p}
\end{aligned}
$$

Where $Q_{k p}=h_{k p}\left(T_{k}-T_{p}\right)$ stands for interphase heat exchange coefficient. $h_{k p}$ is the heat transfer coefficient between phases.

Lotfi et al. ${ }^{106}$ applied the two-phase Eulerian approach in horizontal conduits with alumina-based nanofluid for forced convection flow and noted that both single-phase and Eulerian underestimated the value of the Nusselt number. Bég et al. ${ }^{107}$ examined the bio nanofluid in a circular channel to study the heat transfer and elaborated that the difference between the results of single-phase and experiments was $35 \%$ but for a Eulerian model, it was only $7 \%$. A study was done by Hejazian et al. ${ }^{108}$ to compare the Eulerian and mixture models for nanofluid turbulent flow. This reveals that both models almost provide the same results.

Ebrahimnia-Bajestan et al. ${ }^{109}$ investigated the $\mathrm{TiO}_{2} /$ water nanofluid in a solar heat exchanger to calculate heat transfer characteristics using single-phase, mixture and Eulerian models. The results indicated that for accurate experimental data, the Eulerian model is not recommended, so they modified the common mixture model for better results.

- Eulerian-Lagrangian Model: In the EulerianLagrangian model, by using the particle motion theory given in the Lagrangian reference frame, ${ }^{110}$ the fluid phase is considered as a continuum medium by solving the momentum equations and the particle phase is modeled by solving for individual particle motion. The influence of particles in the fluid is introduced as source terms in the momentum and energy equations. Mass, energy and momentum can be exchanged by the dispersed phase with the fluid phase.

A limitation of this model is that it requires more computational time and high memory. Many research studies have been done using the Eulerian-Lagrangian approach to simulate nanofluid flow and heat transfer. As this approach can handle limited numbers of nanoparticles, it is the most suitable for modeling the micromechanics of a nanofluid flow on a scale of up to about one million particles. The Eulerian-Lagrangian approach was used by Rashidi et al. ${ }^{111}$ inside a channel equipped with square blocks, to simulate fluid flow and heat transfer. In this a mixture of alumina particles (having concentration of $1 \%$ and size between $30 \mathrm{~nm}$ and $0.5 \mu \mathrm{m}$ ) and water is taken as working fluid and ANSYS-Fluent software was used to solve the problem.

\subsection{Review of Hybrid Nanofluids}

Publication statistics for the last five years shows that the field of nanofluid is drawing significant attention of scholars and researchers. Due to superior thermophysical properties of hybrid nanofluid over unitary nanofluids, a strong interest towards this field has been mobilized. Application areas of hybrid nanofluids are varied widely and include heat transfer in electronic cooling, thermal storage, biomedical, drug reduction, heat pipes, refrigeration etc. As far as hybrid nanofluid applications in industry are concerned, they have better efficiency than unitary nanofluids. Moreover, adding to research articles, some books also have been published for the properties and application of nanofluids. ${ }^{112-114,124-126}$ Some existing literature for hybrid nanofluids is presented in Table IV.

\subsection{Rheological Behavior of Nanofluids}

For any fluid, this behaviour is used to express the relationship between shear stress and strain rate. The ratio of shear stress to the strain rate is called viscosity, which is a measure of its resistance to deformation at a given rate during flow. Convective heat transfer and pressure drop of nanofluids are affected by rheological behavior. Further, this behavior also depends on nanoparticle structuring, which is a key-point for the prediction of thermal conductivity. Based on the nature of viscosity, fluid behavior is classified as Newtonian and non-Newtonian. The Newtonian fluids follow the Newton's viscosity law, which is a linear relationship between shear stress and strain rate. Fluids that do not follow this law are called non-Newtonian. The model of non-Newtonian fluid is divided into three groups, named time-independent, time-dependent and viscoelastic fluids.

\section{- Newtonian and non-Newtonian behavior}

- To understand the rheological behavior of nanofluid, many studies have been done, in which some researchers

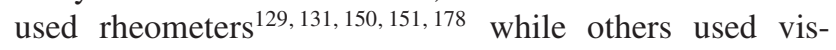
cometers to measure the viscosity. ${ }^{127,128}$ Nowadays the use of viscometers is found mostly inadequate because in the case of low viscosity liquid-based nanofluid having nonspherical particles, it is not able to easure the feature of shear dependence.

- $\mathrm{TiO}_{2}$ Nanoparticle: He et al. ${ }^{129}$ showed that taking particle volumetric concentration as $0.24,0.6$ and 1.18 in $\mathrm{TiO}_{2}$ /distilled water nanofluid for a $0.1-1000$ shear rate range, suspensions exhibited strong shear thinning behavior until the shear rate reached $100 \mathrm{~s}^{-1}$ and for 
Table IV. Summary of numerical studies on hybrid nanofluids.

\begin{tabular}{|c|c|c|c|c|c|c|}
\hline Reference & $\begin{array}{c}\text { Nano- } \\
\text { Composite }\end{array}$ & $\begin{array}{l}\text { Base } \\
\text { fluid }\end{array}$ & $\begin{array}{l}\text { Volumetric } \\
\text { concentration }\end{array}$ & $\begin{array}{l}\text { Particle } \\
\text { size }\end{array}$ & $\begin{array}{l}\text { Preparation } \\
\text { method }\end{array}$ & Remarks \\
\hline $\begin{array}{l}\text { Toghraie } \\
\text { et al. }{ }^{115}\end{array}$ & $\mathrm{ZnO}, \mathrm{TiO}_{2}$ & $\begin{array}{r}\text { Ethylene } \\
\text { glycol }\end{array}$ & $\begin{array}{l}0.1,0.3,0.5,1.0, \\
1.5,2.0,2.5,3.0, \\
3.5\end{array}$ & - & $\begin{array}{l}\text { Two-step } \\
\text { method }\end{array}$ & $\begin{array}{l}\text { Thermal conductivity increases with } \\
\text { increasing the solid volumetric } \\
\text { concentration and the maximum } \\
\text { enhancement of thermal conductivity } \\
\text { of } \mathrm{ZnO}-\mathrm{TiO}_{2} / \mathrm{EG} \text { hybrid nanofluid } \\
\text { was } 32 \% \text { at a volume fraction of } \\
3.5 \%\end{array}$ \\
\hline $\begin{array}{l}\text { Amiri } \\
\quad \text { et al. }{ }^{116}\end{array}$ & $\mathrm{SiO}_{2}, \mathrm{Cu}$ & $\begin{array}{l}\text { Water/ } \\
\text { Ethylene } \\
\text { glycol }\end{array}$ & - & $50-80 \mathrm{~nm}$ & Ultrasonicating & $\begin{array}{l}\text { By adding the small amount of } \mathrm{Cu} \text { in } \\
\text { the } \mathrm{SiO}_{2} \text { nanoparticles, the thermal } \\
\text { conductivity of water increases } \\
\text { between } 8 \text { and } 11 \% \text { compared to } \\
\text { pure water. For EG the increment } \\
\text { was between } 9 \text { and } 11.5 \%\end{array}$ \\
\hline $\begin{array}{l}\text { Esfahani } \\
\text { et al. }{ }^{117}\end{array}$ & $\mathrm{ZnO}, \mathrm{Ag}$ & Water & $0.125-2 \%$ & - & $\begin{array}{l}\text { Two-step } \\
\text { method }\end{array}$ & $\begin{array}{l}\text { For } \mathrm{ZnO}-\mathrm{Ag}(50 \%-50 \%) \text { hybrid } \\
\text { nanofluid, highest thermal } \\
\text { conductivity was found for } \\
\text { volumetric concentration of } 2 \% \text { at } \\
\text { different temperatures }\end{array}$ \\
\hline $\begin{array}{l}\text { Kumar } \\
\text { et al. }{ }^{118}\end{array}$ & $\mathrm{Cu}, \mathrm{Zn}$ & $\begin{array}{l}\text { Vegetable oil, } \\
\text { Paraffin oil, } \\
\text { SAE oil }\end{array}$ & $0.1,0.3,0.5$ & $25 \mathrm{~nm}$ & $\begin{array}{l}\text { Ultrasonication } \\
\text { method }\end{array}$ & $\begin{array}{l}\text { Thermal conductivity with vegetable oil } \\
\text { base fluid is more increased in } \\
\text { comparison with others (due to } \\
\text { higher viscosity and lower thermal } \\
\text { conductivity of Paraffin oil and SAE } \\
\text { oil) and vegetable oil showed } \\
\text { Newtonian nature. }\end{array}$ \\
\hline $\begin{array}{l}\text { Esfe } \\
\quad \text { et al. }{ }^{119}\end{array}$ & DWCNT, $\mathrm{SiO}_{2}$ & $\begin{array}{r}\text { Ethylene } \\
\text { glycol }\end{array}$ & $\begin{array}{l}0.03,0.06,0.12 \\
0.25,0.38,0.65 \\
1.15,1.71\end{array}$ & $\begin{array}{l}30 \mathrm{~nm} \text {, For } \\
\text { DWCNT, inner } \\
\text { diameter } \\
1-3 \mathrm{~nm} \text {, outer } \\
2-4 \mathrm{~nm}\end{array}$ & $\begin{array}{l}\text { Ultrasonication } \\
\text { method }\end{array}$ & $\begin{array}{l}\text { At } 1.71 \% \text { volume fraction, thermal } \\
\text { conductivity of hybrid nanofluid } \\
\left(\mathrm{SiO}_{2}, \mathrm{DWCNT} / \mathrm{EG}\right) \text { is found } 38 \% \\
\text { more than that of base fluid and } \\
\text { DWCNT-SiO} / \text { /EG hybrid nanofluid } \\
\text { is more efficient than DWCNT/EG } \\
\text { nanofluid economically. }\end{array}$ \\
\hline $\begin{array}{l}\text { Aberoumand } \\
\text { and } \\
\text { Jafarimog- } \\
\text { haddam }^{120}\end{array}$ & $\mathrm{Ag}, \mathrm{WO}_{3}$ & $\begin{array}{l}\text { Transformer } \\
\text { oil }\end{array}$ & $1.0,2.0,4.0$ & $60 \mathrm{~nm}$ & $\begin{array}{l}\text { One-step } \\
\text { method }\end{array}$ & $\begin{array}{l}\text { Transformer oil is used because of its } \\
\text { high heat transfer rate and silver, due } \\
\text { to the high capability in thermal } \\
\text { conductivity. For } 4 \% \text { wt volume } \\
\text { fraction, thermal conductivity of } \\
\text { hybrid nanofluid is enhanced by } 41 \%\end{array}$ \\
\hline $\begin{array}{l}\text { Rostamian } \\
\text { et al. }{ }^{121}\end{array}$ & $\mathrm{CuO} / \mathrm{SWCNT}$ & $\begin{array}{l}\text { Ethylene } \\
\text { glycol and } \\
\text { water } \\
(40: 60)\end{array}$ & $\begin{array}{l}0.02,0.05,0.1 \\
0.25,0.5,0.75\end{array}$ & $\begin{array}{l}40 \mathrm{~nm} \text {. For } \\
\text { SWCNT inner } \\
\text { diameter } 2 \mathrm{~nm}\end{array}$ & - & $\begin{array}{l}\text { Thermal conductivity of } \\
\text { CuO-SWCNT-EG water (40:60) } \\
\text { hybrid nanofluid increased with } \\
\text { increase in volume fraction and slope } \\
\text { of the increase does not follow } \\
\text { similar trend for different volume } \\
\text { fractions. }\end{array}$ \\
\hline $\begin{array}{l}\text { Akilu } \\
\quad \text { et al. }{ }^{122}\end{array}$ & $\mathrm{TiO}_{2}, \mathrm{CuO} / \mathrm{C}$ & $\begin{array}{r}\text { Ethylene } \\
\text { glycol }\end{array}$ & $0.5,1.0,1.5,2.0$ & $20-26 \mathrm{~nm}$ & $\begin{array}{l}\text { Two-step } \\
\text { method }\end{array}$ & $\begin{array}{l}\mathrm{TiO}_{2} \text { is inexpensive, non-toxic but have } \\
\text { low thermal conductivity and } \mathrm{CuO} / \mathrm{C} \\
\text { has good thermal properties, hence } \\
\text { its combination is studied and highest } \\
\text { increment in thermal conductivity is } \\
\text { found to be } 16.7 \% \text { at } 2 \% \text { volume } \\
\text { fraction. }\end{array}$ \\
\hline $\begin{array}{l}\text { Qing } \\
\quad \text { et al. }{ }^{123}\end{array}$ & $\mathrm{SiO}_{2}$, GNPs & $\begin{array}{l}\text { Transformer } \\
\text { oil }\end{array}$ & $0.01,0.04,0.08$ & $12 \mathrm{~nm}$ & $\begin{array}{l}\text { Two-step } \\
\text { method }\end{array}$ & $\begin{array}{l}\text { Coating of } \mathrm{SiO}_{2} \text { nanoparticles on } \\
\text { graphene surface inhibit the thermal } \\
\text { conductivity, due to its insulating } \\
\text { behaviour while maintaining } \\
\text { excellent thermal properties of } \\
\text { graphene. Viscosity of hybrid } \\
\text { nanofluid was higher than pure fluid } \\
\text { and highest increment in thermal } \\
\text { conductivity is about } 80 \% \text { for } 0.04 \% \\
\text { nanoparticle volume fraction. }\end{array}$ \\
\hline
\end{tabular}


$100 \mathrm{~s}^{-1}-1000 \mathrm{~s}^{-1}$ it Newtonian behavior was recorded. Chen et al. ${ }^{130,131}$ experimented on $\mathrm{TiO}_{2} / E G$ nanofluid for different $\varphi$ and for different shear rate range. For $\varphi$ having $0.1,0.21,0.42,0.86$ and 1.8 values and a shear rate range as $0-200,{ }^{130}$ they found that nanofluid behaved as Newtonian fluid and viscosity was dependent on nanoparticle concentration but independent of temperature while for $\varphi$ as $0.5,2$ and 8 with shear rate range $0.5-10^{4} 131$ viscosity is dependent on both temperature and nanoparticle concentration. With $\mathrm{TiO}_{2}$ /water nanofluid Alphonse et al. ${ }^{132}$ studied the flow behavior for various $\varphi$ in the shear rate range between $0-100$ and found that for this range, nanofluid showed Newtonian behavior but as shear rate range increased, it exhibited shear thinning behavior.

- $\mathrm{SiO}_{2}$ Nanoparticle: Chevalier et al. ${ }^{133}$ used $\mathrm{SiO}_{2}$ nanoparticles with ethanol base fluid having volumetric concentration as 1.1-7.0 and found that this nanofluid exhibited a Newtonian behavior over a wide range of shear rates and also increment in nanoparticle concentration increased viscosity. Anoop et al. ${ }^{134}$ analysed the $\mathrm{SiO}_{2}$ nanoparticle with paraffinic mineral oil for 1.0 and 2.0 volumetric concentration in 1-1000 shear rate range. Nanofluid showed Newtonian nature at $\sim 30{ }^{\circ} \mathrm{C}$ but shear thinning nature was observed at $\sim 100{ }^{\circ} \mathrm{C}$ temperature and pressure. Moreover, viscosity of nanofluid also increased for higher value of pressure.

- $\mathrm{Al}_{2} \mathrm{O}_{3} \quad$ Nanoparticle: Tseng 14 and $\mid \mathrm{Wu}^{135} 0$ took $\mathrm{Al}_{2} \mathrm{O}_{3}$ /double distilled water nanofluid having particle size $0.2 \mu \mathrm{m}$ for $1-1000$ shear rate range and noted that nanofluid exhibited shear thinning nature at low shear rate but after a critical value of shear rate it followed shear thickening behavior. Gallego et al. ${ }^{136}$ studied the effect of $\mathrm{Al}_{2} \mathrm{O}_{3} / \mathrm{EG}$ nanofluid for $0.005-0.066$ volumetric concentration and for $123 \mathrm{~s}^{-1}$ shear rate. This suspension exhibited Newtonian nature at given rate and its viscosity decreased with increase in temperature and increased with $\varphi$.

- $\mathrm{CuO}$ Nanoparticle: Kwak and $\mathrm{Kim}^{137}$ analysed $\mathrm{CuO} / \mathrm{EG}$ nanofluid in the $10^{-5}-10^{-1}$ volumetric concentration range having particle size $10-30 \mu \mathrm{m}$. Nanofluid was found to have very strong shear thinning nature and at very higher shear rate; viscosity of both base fluid and nanofluid posses the same value. Naik et al. ${ }^{138}$ experimented on $\mathrm{CuO} /(\mathrm{PG}+$ water) nanofluid in 60:40 ratio for various volumetric concentrations in a shear rate range 500-700 for particle size less than $50 \mu \mathrm{m}$. In this research, they found that the nanofluid displayed Newtonian nature and viscosity decreased exponentially with the temperature rise. Saeedinia et al. ${ }^{139}$ studied CuO/oil nanofluid for $0.2,0.5,1.0$ and $2.0 \mathrm{wt} \%$ volumetric concentrations for shear rate range $1-17$. In their findings, they illustrated that at even different temperatures nanofluid showed a Newtonian nature and viscosity decreased with a rise in temperature.

- Graphite Nanoparticle: Wang et al. ${ }^{140}$ used Graphite/oil nanofluid for $0.1-1000 \mathrm{~s}^{-1}$ shear rate range and within $0.17-1.36$ range of volumetric concentration. They observed that for a wide range of shear rate the nanofluid exhibited shear thinning nature and inclusion of graphite nanoparticles and surfactant increased the viscosity. Duan et al. ${ }^{141}$ analysed graphite nanoparticles with deionized water for volumetric concentration 1-4 and shear rate range $1-100 \mathrm{~s}^{-1}$ and found that nanofluid exhibited a shear thinning nature. It was also found that at same nanoparticle concentration, enhancement in viscosity of nanofluid, held for 3 days, was much more than nanofluids that were prepared recemtly. Moghaddam et al. ${ }^{142}$ used graphene/glycerol nanofluid having particle size $15-50 \mu \mathrm{m}$ in a shear rate range $1-180 \mathrm{~s}^{-1}$. They found that for high shear rate, the suspension behaved as Newtonian fluid but for low shear rate, the nanofluid had shear thinning nature.

- Multi-walled Carbon Nano-Tube (MWCNT):

- Potschke et al. ${ }^{143}$ experimented on $0.5,1,2$ and 5 wt\% volumetric concentration of $M W C N T /$ polycarbonate nanofluid and highlighted that at lower frequencies, nanofluids containing more than 2 wt $\%$ MWCNT displayed non-Newtonian behavior while for 0.5 and $1 \%$ they showed Newtonian behavior. Yang et al. ${ }^{144}$ used the MWCNT/poly $\alpha$-olefin(PA06) oil nanofluid for 100 shear rate and demonstrated that the nanoparticles with highest $(8 \%)$ and lowest $(0.3 \%)$ dispersant concentrations showed strong non-Newtonian behavior while with $3 \mathrm{wt} \%$ dispersant they showed a Newtonian nature. Seyhan et al. ${ }^{145}$ studied the MWCNT/vinyl ester-polyster based nanofluid for $10^{-1}-10^{3} \mathrm{~s}^{-1}$ shear rate range and concluded that pure resin fluid exhibited Newtonian behavior but with the addition of $M W C N T$ nanoparticles, it had shear thinning behavior. For $M W C N T-\mathrm{Al}_{2} \mathrm{O}_{3} /$ glycerol and water based nanofluid, $\mathrm{Lu}^{146}$ experimented with various $\varphi$ and 1$200 \mathrm{~s}^{-1}$ shear rate range. They found that with increase in nanoparticle concentration, viscosity also increased and both $\mathrm{Al}_{2} \mathrm{O}_{3}$ and $M W C N T-\mathrm{Al}_{2} \mathrm{O}_{3}$ suspensions displayed a shear thinning nature.

- Phuoc et al. ${ }^{147}$ used $M W C N T /$ deionized water nanofluid having volumetric concentration in range of 0.24-1.43 in their study and proved that for low CNT concentration $(0.24 \mathrm{vol} \%$ and $0.1-0.2 \mathrm{wt} \%)$, it behaved as Newtonian fluid while for high $\varphi$, shear thinning nature has been exhibited. In parallel research, Ruan and Jacobi ${ }^{148}$ took $M W C N T / E G$ nanofluid having $0.5 \mathrm{wt} \%$ volumetric concentration and in $0.1-100 \mathrm{~s}^{-1}$ shear rate range. Their study reveals that generally the nanofluid shows shear thinning behavior and at a fixed shear rate first the viscosity of fluid increased then decreased with an increase in sonication time. Wang et al. ${ }^{149}$ studied the $M W C N T /$ deionized water nanofluid for $\varphi$ of $0.05,0.24$, 1.27 and shear rate range from 1 to $200 \mathrm{~s}^{-1}$ and concluded that nanofluid displayed a shear thinning nature at a high volumetric concentration. Moreover, viscosity decreased with increasing temperature but increased with a rise in concentration. 
- Hybrid Suspension of $\mathrm{TiO}_{2}$ Nanoparticle: Richmond et al. ${ }^{127}$ conducted a study for $\mathrm{SiO}_{2}$ and $\mathrm{TiO}_{2}$ nanoparticles in deionized water having 0.468 volumetric solid concentration $(\varphi)$ and found that the $\mathrm{SiO}_{2} /$ water nanofluid demonstrated Newtonian behavior while the hybrid suspension of nanoparticles exhibited Bingham plastic nonNewtonian behavior. Further, the addition of $\mathrm{TiO}_{2}$ particles increased the viscosity significantly in comparison with pure $\mathrm{SiO}_{2}$ suspension. Chen et al. ${ }^{150}$ presented another study for $\mathrm{TiO}_{2} /$ water, $\mathrm{TiO}_{2} / E G, T N T /$ water and TNT/EG nanofluids having $\varphi$ of $0-2$ with shear rate range $0.03-$ $3000 \mathrm{~s}^{-1}$. They found that only $\mathrm{TiO}_{2} / E G$ nanofluid showed Newtonian behavior while the other three nanofluids displayed non-Newtonian behavior. Hojjat et al. ${ }^{152}$ conducted a study for $\mathrm{Al}_{2} \mathrm{O}_{3}, \mathrm{TiO}_{2}, \mathrm{CuO}$ nanoparticles with aqueous solution of CMC base fluid for $350-1000 \mathrm{~s}^{-1}$ shear rate range having different particle size also and observed that nanofluid with all nanoparticles followed shear-thinning behavior and that viscosity of $\mathrm{TiO}_{2}, \mathrm{Al}_{2} \mathrm{O}_{3}$ nanofluids are dependent on nanoparticle volume fraction while $\mathrm{CuO}$ nanofluid is found to be independent in nature of it.

- Hybrid Suspension of $\mathrm{SiO}_{2}$ and $\mathrm{Al}_{2} \mathrm{O}_{3}$ Nanoparticle: Tavman et al. ${ }^{153}$ studied the $\mathrm{SiO}_{2} /$ deionized water and $\mathrm{Al}_{2} \mathrm{O}_{3}$ /deionized water nanofluid for various volumetric concentrations and concluded that viscosity is proportional to nanoparticle concentration but inversely proportional to temperature. Hybrid $\mathrm{ICH}$ and $\mathrm{ASCH} /$ aqueous 5 wt\% bentonite nanofluid for $1-200 \mathrm{~s}^{-1}$ shear rate range has been studied by Jung et al. ${ }^{154}$ and it has been demonstrated that all clay-dependent based fluids posses a strong shear thinning nature.

\section{- Study on Distinctive Nanoparticles:}

- $\mathrm{BaTiO}_{3}$ and distilled water based nanofluid having shear rate range $1-1000 \mathrm{~s}^{-1}$ was analyzed by Tseng and $\mathrm{Li}^{155}$ for $0.8 \mu \mathrm{m}$ particle size. The study showed that nanoparticles without $\mathrm{NH}_{4} \mathrm{PA}$ exhibited shear thinning nature but behaved as Bingham plastic as shear rate exceeded $\sim 400 \mathrm{~s}^{-1}$. By adding $\mathrm{NH}_{4} \mathrm{PA}$ in conventional fluid, the fluid appeared to be Newtonian nature for even low shear rate $\left(\sim 100 \mathrm{~s}^{-1}\right)$.

- Tseng and Chen ${ }^{156}$ used Nickel nanoparticles with terpineol base fluid for $0.03-0.1$ volumetric concentration and for 1-1000 $\mathrm{s}^{-1}$ shear rate range and found that nanofluid containing nickel powder showed shear-thinning nature for all values of shear rate. Mary et al. ${ }^{157}$ conducted an experiment for Aluminium/HTPB, PPg and PSi nanofluid for particle size $120 \mu \mathrm{m}$ and shear rate range $10^{-3}-10^{3} \mathrm{~s}^{-1}$. Results indicated that uncoated HTPB suspension in base fluid exhibited Newtonian behavior while the HTPB coated displayed shear-thinning nature for volumetric concentration 6.25 and 10 vol\%. Moreover, shearthinning nature was also observed for both PPG and PSi suspended nanofluid. Tamjid and Guenthe ${ }^{158}$ used silver as nanoparticle of size $40 \mu \mathrm{m}$ with DEG base fluid having $\varphi$ in range of $0.11-4.38$. They reported that nanofluid demonstrated pseudoplastic (non-Newtonian) flow behavior and viscosity is proportional to particle concentration.

- Tseng and Tzeng ${ }^{159}$ conducted a study for ITO and deionized water nanofluid in $0.2-0.3$ volumetric concentration and in $10-500 \mathrm{~s}^{-1}$ shear rate range. The study revealed that for lower shear rate, nanofluid exhibited Bingham fluid (viscoplastic) characteristics while for very high shear rate, it exhibited shear thickening behavior. Zhu et al. ${ }^{160}$ using $\mathrm{CaCO}_{3}$ /distilled water nanofluid observed a Newtonian nature for a various volumetric concentration $(0.12,0.48,1.40,2.05,4.11)$ over a $5-100 \mathrm{~s}^{-1}$ shear rate range. Xie et al. ${ }^{161}$ analysed the $\mathrm{MgO} / \mathrm{EG}$ nanofluid having particle size $20 \mu \mathrm{m}$ in $10-150 \mathrm{~s}^{-1}$ shear rate range and concluded that it behaved as Newtonian fluid, the viscosity in-creased with the rise of nanoparticle volume fraction but decreased with an increase in temperature. Meng et al. ${ }^{162}$ used carbon black powder (N115) with Ethylene glycol for volumetric concentration 2.2, 5.6, 7.8 in shear rate range 6-120 $\mathrm{s}^{-1}$. In their findings they observed that nanofluid showed shear thinning nature and the extent of this nature increased with more addition of carbon black into Ethylene glycol. Moreover, viscosity decreased with rise in temperature. Cholewa et al. ${ }^{163}$ analysed Yttrium oxide $\left(\mathrm{Y}_{2} \mathrm{O}_{3}\right) / \mathrm{EG}$ and magnesium-aluminium spinel $\left(\mathrm{MgAl}_{2} \mathrm{O}_{4}\right) / \mathrm{EG}$ nanofluid for various volumetric concentration $(1,5,10,15,20$ wt $\%$ ) in 0.01-2000 shear rate-range. The study illustrated that $\mathrm{MgAl}_{2} \mathrm{O}_{4}$ nanoparticle exhibited Newtonian nature for low volumetric concentration while for higher concentration it showed shear thinning behavior. Furthermore, $\mathrm{Y}_{2} \mathrm{O}_{3}$ nano-fluid exhibited a non-Newtonian nature and temperature did not affect the viscosity of $\mathrm{MgAl}_{2} \mathrm{O}_{4}$ suspension.

\section{- Magneto-Rheological behavior of Nanofluid:}

- $\mathrm{Fe}_{3} \mathrm{O}_{4}$ Nanoparticle: Hong et al. ${ }^{164}$ used $\mathrm{Fe}_{3} \mathrm{O}_{4}$ magnetic particle with deionized water for $10,15,25,35$ wt\% volumetric concentration in $1-100 \mathrm{~s}^{-1}$ shear rate range. Results expressed that for 10 and $15 \mathrm{wt} \%$ nanofluid exhibited Newtonian nature, with increasing volumetric concentration the behavior changed. For $25 \mathrm{wt} \%$ it behaved as shear thickening fluid while for $35 \mathrm{wt} \%$ it showed a shear thinning nature. Zafarani-Moattar and Majdan-Cegincara ${ }^{165}$ showed that $\mathrm{Fe}_{3} \mathrm{O}_{4}$ /polyethylene glycol (PEG) nanofluid exhibited shear-thinning nature for a various volumetric concentration $(0.48,1.0,3.05,3.6)$ over a $0.01-1000 \mathrm{~s}^{-1}$ shear rate range.

- $\mathrm{Fe}_{2} \mathrm{O}_{3}$ Nanoparticle: Phuoc and Massoudi ${ }^{166}$ analysed $\mathrm{Fe}_{2} \mathrm{O}_{3}$ (Ferric Oxide)/deionized water nanofluid having particle size of $20-40 \mu \mathrm{m}$ for $13.2-264 \mathrm{~s}^{-1}$ shear rate range. The research showed that nanofluid having volumetric concentration less than 0.02 showed Newtonian nature but for higher concentration it displayed shear 
thinning property. Pastoriza-Gallego et al. ${ }^{167}$ found that $\mathrm{Fe}_{2} \mathrm{O}_{3} / \mathrm{EG}$ nanofluid exhibited shear thinning nature and also thixotropic behavior for a volumetric concentration 6.6 over a $1-1000 \mathrm{~s}^{-1}$ shear rate range. $\mathrm{Fe}_{2} \mathrm{O}_{3}$ and glycerol based nanofluid was studied by Abareshi et al. ${ }^{168}$ for 0.25-0.8 volumetric concentration and for 0.01-264 shear rate range. Results indicated that suspensions showed shear-thinning behavior and viscosity of nanofluid was proportional to concentration but inversely proportional to temperature.

- Study on Various Magnetic Nanoparticles:

- Vekas et al. ${ }^{169}$ used $\gamma-\mathrm{Fe}_{2} \mathrm{O}_{3}$ /iso-butanol and $\gamma$ $\mathrm{Fe}_{2} \mathrm{O}_{3}$ /methyl-ethyl-ketone (MEK) nanofluid having particle size less than $10 \mu \mathrm{m}$ and for a shear rate range from 1 to 1000. Their findings illustrated that MEK-based nanofluid showed shear-thinning nature while Iso-butanol based nanofluid exhibited Newtonian nature. The increase in magnetic field did not affect the iso-butanol nanofluid rheological behavior but it strongly affected the MEK based nanofluid.

- Susan-Resiga et al. ${ }^{170}$ performed a numerical investigation to study the effect of Magnetite/transformer oil nanofluid having particle size 6-7 $\mu \mathrm{m}$ and at volumetric concentration 0.8-21. It was found that all suspensions behaved as Newtonian fluid except for the $20.8 \%$ volumetric concentration and nanofluid viscosity increased with particle concentration. In the same manner, Katiyar et al. ${ }^{171}$ investigated the $\mathrm{Fe}-\mathrm{Ni}$ nanoparticles having particle size less than $15 \mu \mathrm{m}$ with paraffin oil base fluid for $2-12 \mathrm{wt} \%$ volumetric concentration. They found that without magnetic field, the suspension with $10 \mathrm{wt} \%$ loading exhibited pseudoplastic behavior but as magnetic field increased, the fluid behaved as Bingham plastic.

The above presented review has focused on the rheological behavior of nanofluid for a wide range of nanoparticle volumetric concentration and shear rate range with or without the influences of magnetic field. It has been seen that mostly nanofluids with low shear rate range and having low nanoparticle volumetric fraction display a Newtonian nature while for high shear-rate range and high volumetric fraction, non-Newtonian behavior is seen. Further, a deviation from Newtonian to non-Newtonian nature has been found in nanofluids while applying a external magnetic field. This rheological behavior of nanofluid plays a major role in blood flow problems in arterial system.

\section{REVIEW OF COMPUTATIONAL BIO-NANO FLUID FLOWS}

The accumulation of fatty substances or the formations of plaques inside the lumen narrow the arterial vessel, resulting to cardiac-related problems. This narrowing of the arteries is termed as stenosis. As hardening of the artery causes the blood clot formation, which further reduces the blood flow to the heart. This reduction of the blood flow can cause severe problems like a heart attack or stroke to the human body. Regardless of the reasons, these obstructions may cause changes in significant parameters such as in pressure distribution, flow resistance and wall shear stress. Chakravarty and Mandal ${ }^{172}$ analyzed the nonNewtonian blood flow in an artery with stenosis considering unsteady behavior. In this study overlapped stenosis is taken while blood presents the viscoelastic nature. In one of the study, Mandal ${ }^{173}$ showed that blood exhibits non-Newtonian characteristics in particular some diseases like cerebrovascular diseases, myocardial infarction or in hypertension. The tapering of the blood vessel is found to be another important factor. Chakravarty and Mandal ${ }^{174}$ studied a mathematical model for a tapered blood vessel in which blood flowing through is considered as incompressible Newtonian fluid. The arterial vessel wall has elasticity and overlapping stenosis is taken for the geometry. Additionally, Tripathi ${ }^{175}$ presented a study on three layered oscillatory blood flow through an arterial stenosis segment.

As it is known that blood vessel wall can be elastic or permeable. Hence the understanding of the basic mechanics of fluid is essential to figure out the mechanism involved in circulation of blood. Naz et al., ${ }^{176}$ Shukla et al., ${ }^{177}$ Hameed and Rahman ${ }^{178}$ and Ellahi et al. ${ }^{179}$ etc. are the basic studies considering various models of Newtonian/non-Newtonian fluids. The thickness of the arterial walls are mostly smooth and uniform in nature and in normal artery, erythrocytes (RBC), leukocytes (WBC) and other particles move freely towards the peripheral organs. Nadeem and Akbar ${ }^{180,181}$ performed various theoretical studies for blood flow through different stenosis. Several investigators like, Mekheimer and El kot ${ }^{182}$ and Mekheimer et al. ${ }^{183}$ have highlighted the different aspects of blood flow analysis in arteries. For mathematical model representing the overlapped stenosed artery, the behaviour of blood flow was examined by Riahi et al. ${ }^{184}$. Furthermore, Ellahi et al. ${ }^{185}$ conducted a theoretical study for blood flow through an arterial segment under the composite stenosis and by considering blood as non-Newtonian micropolar fluid.

A catheter is composed of medical grade polyvinyl chloride and polyester based thermoplastic polyurethane, etc. and an annular region is formed between the catheter wall and arterial wall by the inclusion of catheter. Catheterization process can change the hemodynamic conditions and blood flow inside the blood vessel. In reference to this, various studies have been explored by researchers. Srivastav ${ }^{186}$ studied the blood flow phenomenon through the catheterized composite stenosis and the arterial walls have permeability effects. Blood is considered as Newtonian fluid inside the catheterized artery and for the flow characteristics, permeability effects are discussed. Srivastava and Srivastava ${ }^{187}$ exhibited a mathematical model for catheterization inside the artery for both cases, 
Table V. Summary of various blood flow models with/without nanoparticles.

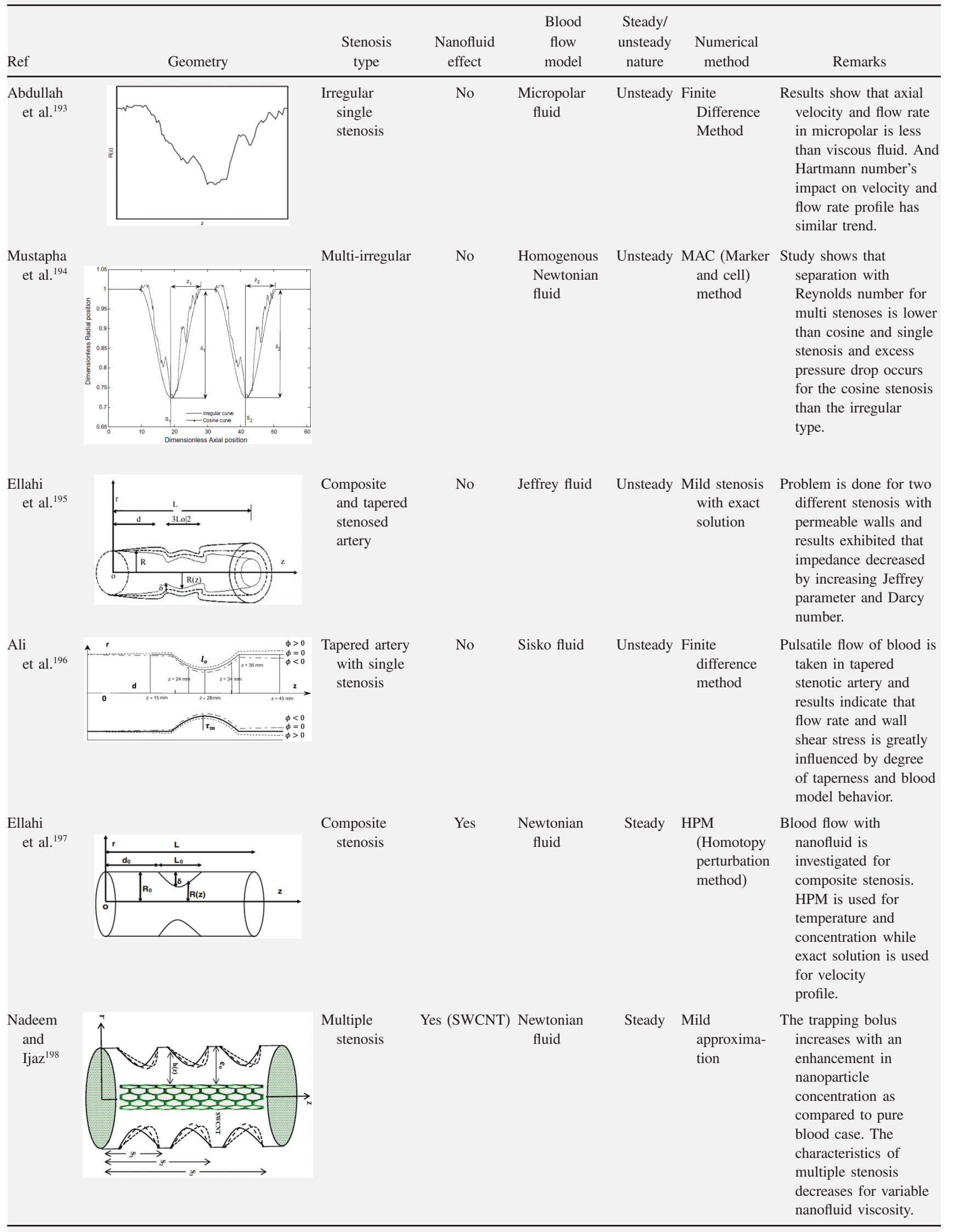


Table V. Continued.

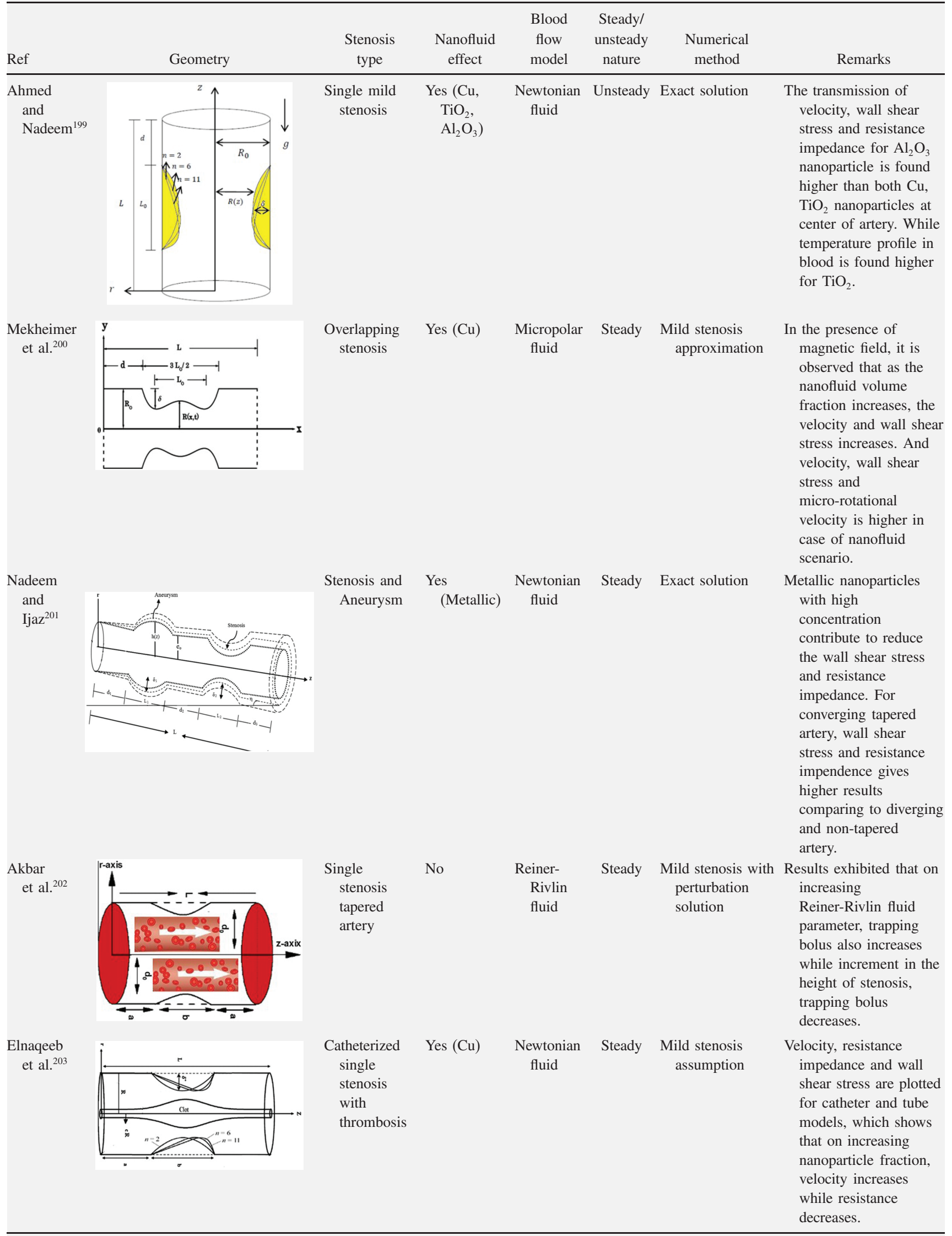


Table V. Continued.




Table V. Continued.

\begin{tabular}{|c|c|c|c|c|c|c|c|}
\hline Ref & Geometry & $\begin{array}{l}\text { Stenosis } \\
\text { type }\end{array}$ & $\begin{array}{l}\text { Nanofluid } \\
\text { effect }\end{array}$ & $\begin{array}{l}\text { Blood } \\
\text { flow } \\
\text { model }\end{array}$ & $\begin{array}{l}\text { Steady/ } \\
\text { unsteady } \\
\text { nature }\end{array}$ & $\begin{array}{l}\text { Numerical } \\
\text { method }\end{array}$ & Remarks \\
\hline Ahmed and & & \multirow{2}{*}{$\begin{array}{l}\text { Different } \\
\text { stenosis (6 } \\
\text { type) }\end{array}$} & \multirow[b]{2}{*}{$\begin{array}{l}\text { Yes, } \\
\text { Hybrid } \\
(\mathrm{Cu} \text { and } \\
\left.\mathrm{Al}_{2} \mathrm{O}_{3}\right)\end{array}$} & \multirow{2}{*}{$\begin{array}{l}\text { Micropolar } \\
\text { fluid }\end{array}$} & \multirow[t]{2}{*}{ Steady } & \multirow{2}{*}{$\begin{array}{l}\text { Mild-stenosis } \\
\text { approximation }\end{array}$} & \multirow[b]{2}{*}{$\begin{array}{l}\text { Micropolar fluid with } \\
\text { hybrid } \\
\text { nanoparticles in } 6 \\
\text { types of stenosis is } \\
\text { observed under } \\
\text { magnetic effect and } \\
\text { found that on } \\
\text { increasing } \\
\text { nanoparticle } \\
\text { concentration, } \\
\text { velocity and wall } \\
\text { shear stress } \\
\text { increases. }\end{array}$} \\
\hline Nadeem $^{209}$ & 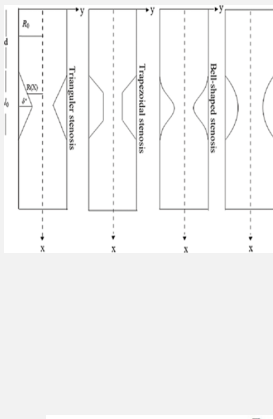 & & & & & & \\
\hline Ijaz et al. ${ }^{210}$ & $/ 2$ & $\begin{array}{l}\text { Overlapped } \\
\text { Stenosis } \\
\text { with } \\
\text { tampering } \\
\text { impact }\end{array}$ & $\begin{array}{l}\text { Yes }(\mathrm{Cu}, \\
\mathrm{CuO})\end{array}$ & $\begin{array}{l}\text { Newtonian } \\
\quad \text { fluid }\end{array}$ & Steady & $\begin{array}{l}\text { Mild-stenosis } \\
\text { Approximation }\end{array}$ & $\begin{array}{l}\text { Results showed that } \\
\text { wall shear stress } \\
\text { and flow resistance } \\
\text { of the stenotic } \\
\text { artery decreases for } \\
\mathrm{Cu}-\mathrm{CuO} \text { /blood } \\
\text { having platelet } \\
\text { shape. For Biot } \\
\text { number, blood } \\
\text { resistance increases } \\
\text { and hemodynamics } \\
\text { give minimum } \\
\text { results for no-slip } \\
\text { case. }\end{array}$ \\
\hline Ali et al. ${ }^{211}$ & $\stackrel{r_{1}}{\rightarrow}$ & $\begin{array}{l}\text { Tapered } \\
\text { overlapping } \\
\text { stenosis }\end{array}$ & Yes & Sisko fluid & Unsteady & $\begin{array}{l}\text { Mild stenosis } \\
\text { assumption } \\
\text { with FTCS } \\
\text { (forward time } \\
\text { central spacing) }\end{array}$ & $\begin{array}{l}\text { Results are validated } \\
\text { with FEM and } \\
\text { found that an } \\
\text { increment in the } \\
\text { Brownian motion } \\
\text { parameter caused a } \\
\text { reduction in flow } \\
\text { rate at the stenotic } \\
\text { throat. }\end{array}$ \\
\hline Zaman et al. ${ }^{212}$ & & $\begin{array}{l}\text { Stenosis and } \\
\text { Aneurysm } \\
\text { in curved } \\
\text { artery }\end{array}$ & $\begin{array}{l}\text { Yes }(\mathrm{Cu}, \\
\mathrm{Ag})\end{array}$ & $\begin{array}{l}\text { Newtonian } \\
\quad \text { fluid }\end{array}$ & Unsteady & $\begin{array}{l}\text { FTCS (forward } \\
\text { time central } \\
\text { spacing) } \\
\text { method }\end{array}$ & $\begin{array}{l}\text { Axial velocity profile } \\
\text { in stenotic area } \\
\text { shows symmetric } \\
\text { trend on increasing } \\
\text { curved parameter } \\
R_{\mathrm{c}} \text {. With greater } \\
\text { nanoparticle } \\
\text { volume fraction, } \\
\text { flow rate, velocity } \\
\text { and wall shear } \\
\text { stress increases } \\
\text { while resistance } \\
\text { impedance } \\
\text { decreases. }\end{array}$ \\
\hline $\begin{array}{l}\text { Priyadharshini and } \\
\text { Ponalagusamy }^{213}\end{array}$ & is & $\begin{array}{l}\text { Tapered single } \\
\text { stenosis }\end{array}$ & Yes & $\begin{array}{l}\text { Herschel- } \\
\text { Bulkley } \\
\text { fluid }\end{array}$ & Unsteady & FDM & $\begin{array}{l}\text { Magnetic field and } \\
\text { body acceleration } \\
\text { effects are being } \\
\text { considered in } \\
\text { stenosed artery. } \\
\text { Wall stress and } \\
\text { flow resistance } \\
\text { increased by } \\
\text { increasing yield } \\
\text { stress of fluid and } \\
\text { magnetic field. }\end{array}$ \\
\hline
\end{tabular}


Table V. Continued.

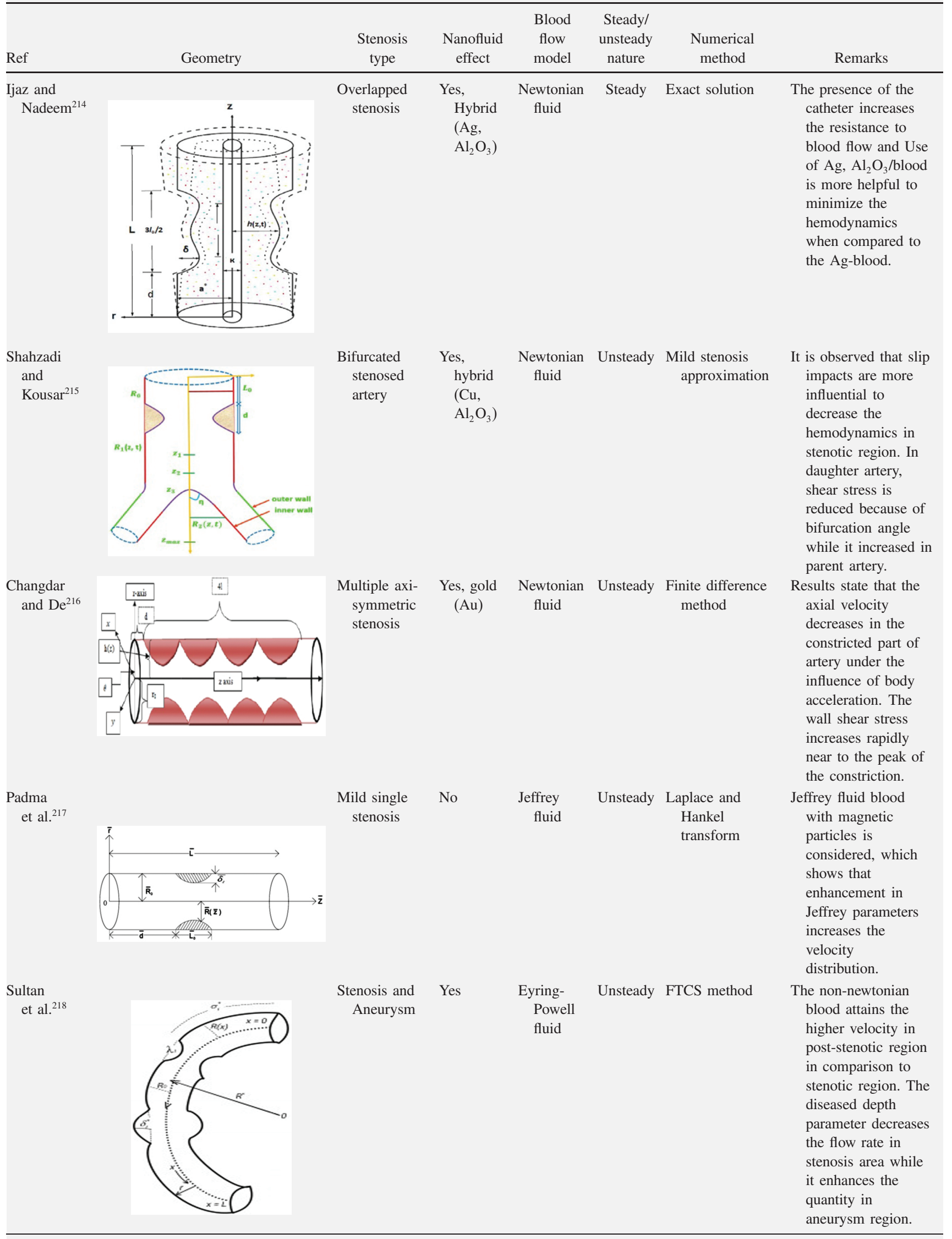


Table V. Continued.

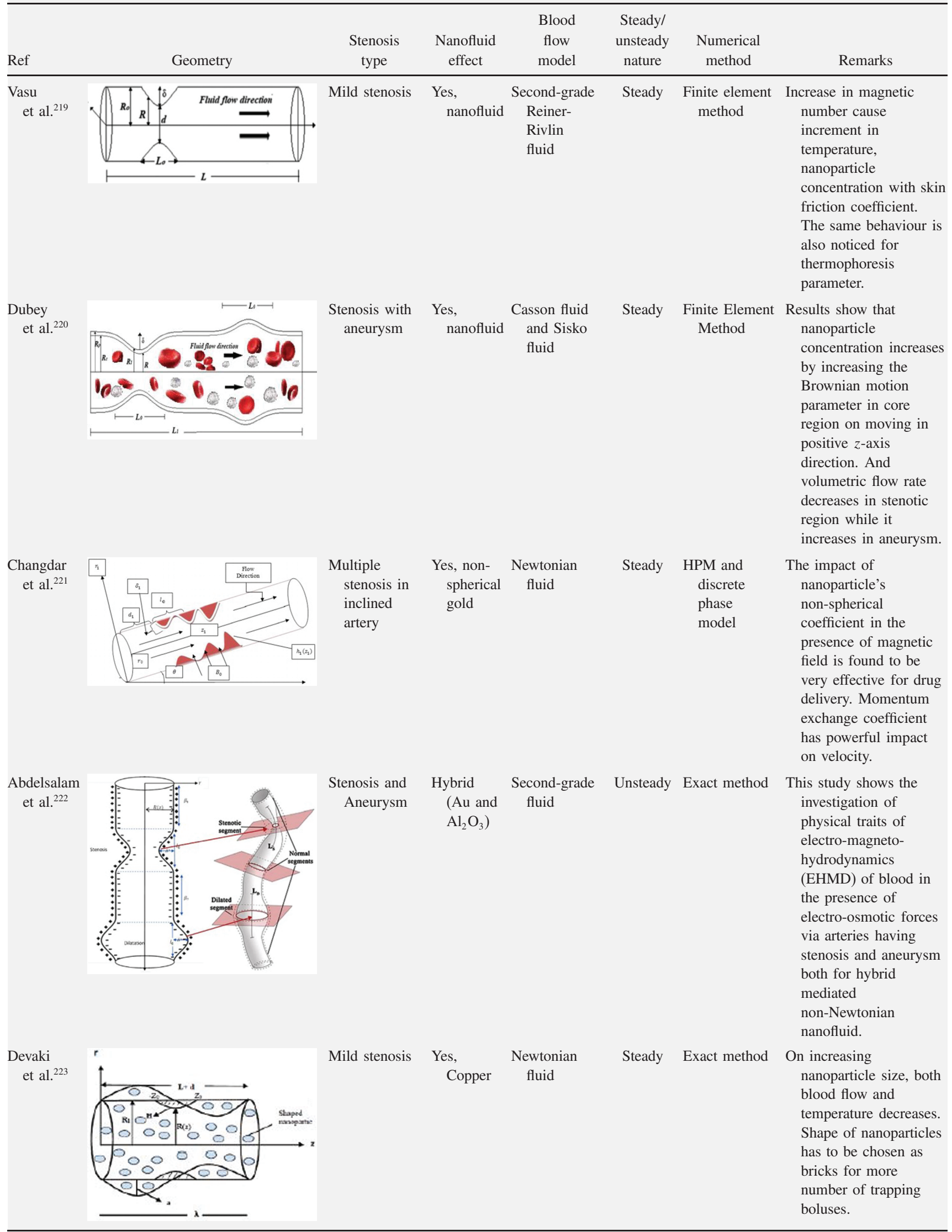


Table V. Continued.

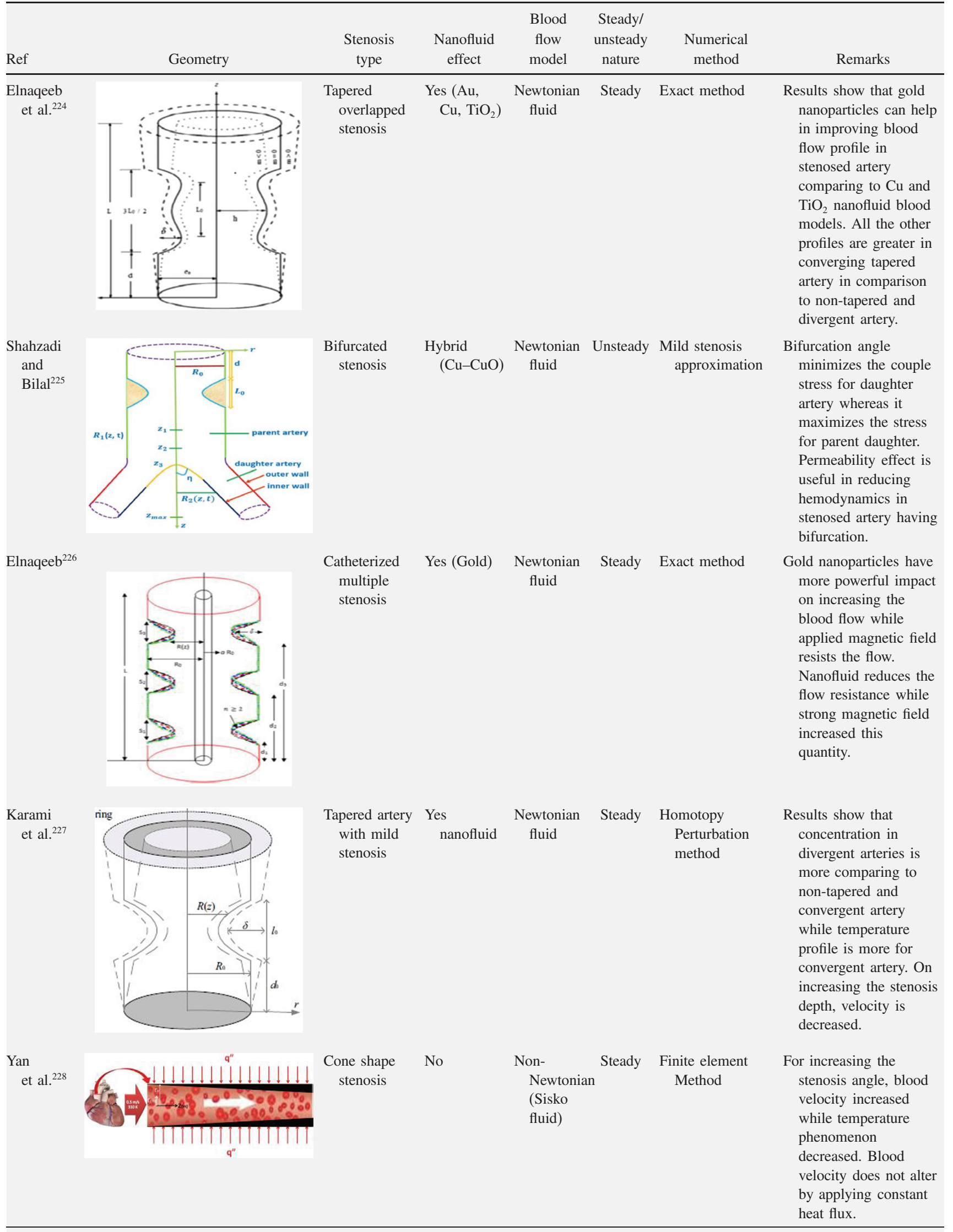


Table V. Continued.

\begin{tabular}{|c|c|c|c|c|c|c|c|c|}
\hline Ref & Geometry & & $\begin{array}{l}\text { Stenosis } \\
\text { type }\end{array}$ & $\begin{array}{c}\text { Nanofluid } \\
\text { effect }\end{array}$ & $\begin{array}{c}\text { Blood } \\
\text { flow model }\end{array}$ & $\begin{array}{c}\text { Steady/ } \\
\text { unsteady } \\
\text { nature }\end{array}$ & $\begin{array}{l}\text { Numerical } \\
\text { method }\end{array}$ & Remarks \\
\hline $\begin{array}{c}\text { Karimipour } \\
\text { et al. }{ }^{229}\end{array}$ & 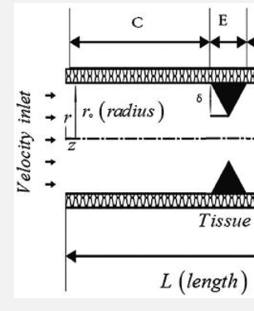 & 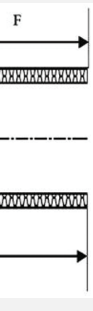 & $\begin{array}{c}\text { Triangular } \\
\text { shape } \\
\text { stenosis }\end{array}$ & No & $\begin{array}{l}\text { Non-Newtonian } \\
\quad \text { (Sisko) }\end{array}$ & Steady & - & $\begin{array}{l}\text { Maximum velocity is } \\
\text { found for different } \\
\text { severity of stenosis } \\
(20 \%, 30 \% \text { and } 40 \%) \\
\text { and with increasing } \\
\text { value of artery radius, } \\
\text { the corresponding } \\
\text { maximum velocity is } \\
\text { subjected to decrease. }\end{array}$ \\
\hline
\end{tabular}

having stenosis and without stenosis. Additionally, Beg et al. ${ }^{188}$ presented a theoretical analysis for boundary layer flow through an impermeable vertical wall in steadystate condition. Nanofluid, having water as base fluid and oxytactic microorganisms as nanoparticles has been considered and it was found that inclusion of nanoparticles enhanced the heat transfer performance of fluid. Further, for the same Reynolds number, increment in volume fraction of nanoparticles also increased the heat transfer. Akbar et al. ${ }^{189}$ presents a study for the simulating viscous blood flow containing copper nanoparticles through a composite stenosed artery. They also employed permeability of arterial wall and thermal buoyancy effects in the study. Sharma et al. ${ }^{190}$ studied a Soret and Dufour effects on blood flow through a stenosed artery. In this, a constant magnetic field is also applied to perpendicular direction of the surface. Bhatti et al. ${ }^{191}$ investigated nanofluid drug delivery in non-uniform porous channel having blood flow. Approximate analytical solutions are derived for physical properties such as temperature, concentration, pressure rise profiles. Srinivasacharya and $\mathrm{RaO}^{192}$ explored the study considering the magnetic field effects in blood flow through a bifurcated artery having mild stenosis. The copper nanoparticles are considered in the study to represent the drug delivery in blood. In this section, literature survey for different arterial stenosis and different blood flow models with nanoparticle effects for drug delivery is presented in Table V.

\section{CONCLUSION}

The present article comprehensively reviews the convective flows of nanoparticles and their influence on blood flow in the human arterial system. From the literature it can be seen that a suspension of nanoparticles can improve the heat transfer capability and pressure drop characteristics. Size, shape and surface irregularities are the most effective parameters for the enhancement of nanofluid performance in biological systems. Statistics have shown that more attention has been given to nanofluids containing a single type of nanoparticle but hybrid nanofluids showed a remarkable increment in performance and are drawing the interest of researchers at a rapid pace. The review comprised of a broad comparison between single-phase and two-phase nanofluid flows to elucidate most suitable approach which gives more accurate results. In comparison to single-phase, two-phase models give the more realistic results because of the consideration of slip mechanisms between the nanoparticles and the base fluid. The influence of some parameters, such as, nanoparticle shape, size, shear rate range and volumetric concentration on the rheological behavior of nanofluid (Newtonian or nonNewtonian) has been observed and has also highlighted some irregularities about the size and shape of the particles. The effect of different nanoparticle concentration, shear rate range, base fluids and nanoparticle shape has also been compiled and analyzed for unitary nanofluid as well as for hybrid nanofluid with or without the influence of magnetic field. Clearly, most of the numerical results showed that nanoparticles of spherical shape exhibit Newtonian nature while tetragonal and tubular shapes show non-Newtonian behavior. The review also extended to mathematical models in the stenotic region for simulating the blood flow containing nanoparticles. According to the findings, stenoses have different geometries, so for various blood flow models and with different nanoparticles, the velocity, temperature, resistance (impedance) and pressure gradient present different results, which is a key factor influencing the effectiveness of nano drug delivery in clinical medicine.

Acknowledgments: The authors are grateful to Science and Engineering Research Board (SERB), Department of Science and Technology (DST), Govt of India for undertaking the research work under the research project File Number: ECR/2017/001053 dated 12/03/2018.

\section{References and Notes}

1. R. L. Whitmore, The dynamics of the circulation. Rheology of the Circulation, Pergamon Press, Oxford, UK (1968), pp. 62-108. 
2. M. J. Manton, J. Fluid Mech. 49, 451 (1971)

3. P. Hall, J. Fluid Mech. 64, 209 (1974).

4. M. H. Friedman, G. M. Hutchins, C. B. Bargeron, O. J. Deters, and F. F. Mark, Atherosclerosis 39, 425 (1981).

5. E. O. Kung, In vitro Experimental Validation of Finite Element Analysis of Blood Flow and Vessel Wall Dynamics, Stanford University (2010).

6. C. Tu, M. Deville, L. Dheur, and L. Vanderschuren, Journal of Biomechanics 25, 1141 (1992)

7. P. Khamdaengyodtai, K. Vafai, P. Sakulchangsatjatai, and P. Terdtoon, Journal of Biomechanics 45, 2577 (2012).

8. https://quickreason.com/what-is-atherosclerosis/.

9. H. Schlicting, Boundary Layer Theory, McGraw-Hill Book Company, New York (1968).

10. D. Biswas, Blood Flow Models: A Comparative Study, Mittal Publications, New Delhi (2000).

11. https://commons.wikimedia.org/wiki/File:Blausen_0425_Formed_ Elements.png.

12. S. C. Ling and H. B. Atabek, J. Fluid Mech. 55, 493 (1972).

13. D. N. Ku, Annual Review of Fluid Mechanics 29, 399 (1997).

14. K. B. Chandran, S. E. Rittgers, and A. P. Yoganathan, Biofluid Mechanics: The Human Circulation, Boca Raton, Taylor \& Francis Group (2012)

15. O. C. Farokhzad and R. Langer, ACS Nano 3, 16 (2009).

16. P. Decuzzi, S. Lee, B. Bhushan, and M. Ferrari, Annals of Biomedical Engineering 33, 179 (2005).

17. J. Tan, S. Shah, A. Thomas, H. D. Ou-Yang, and Y. Liu, Microfluidics and Nanofluidics 14, 77 (2013).

18. F. Irgens, Rheology and Non-Newtonian Fluids, Springer International Publishing, New York, NY, USA (2014), Vol. 190

19. T. Wenchang and $X$. Mingyu, Acta Mechanica Sinica 18, 342 (2002).

20. B. E. Morgan and D. F. Young, Bulletin of Mathematical Biology 36, 39 (1974).

21. D. Liepsch, M. Singh, and M. Lee, Biorheology 29, 419 (1992).

22. J. Sui, L. Zheng, X. Zhang, and G. Chen, Int. J. Heat Mass Transfer 85, 1023 (2015).

23. W. R. Schowalter, Mechanics of Non-Newtonian Fluids, Perrgamon Press, Oxford (1978).

24. H. I. Andersson and F. Irgens, Journal of Non-Newtonian Fluid Mechanics 27, 153 (1988).

25. R. B. Bird, R. C. Armstrong, and O. Hassager, Dynamics of polymeric liquids. Fluid Mechanics (1987), Vol. 1.

26. N. Casson, Rheology of Dispersed Systems, Pergamon Press, Oxford (1959)

27. A. W. Sisko, Ind. Eng. Chem. 50, 1789 (1958).

28. W. H. Herschel and R. Bulkley, Kolloid-Zeitschrift 39, 291 (1926).

29. K. C. Sahu, P. Valluri, P. D. M. Spelt, and O. K. Matar, Physics of Fluids 19, 122101 (2007)

30. S. U. Choi and J. A. Eastman, Enhancing thermal conductivity of fluids with nanoparticles (No. ANL/MSD/CP-84938; CONF951135-29). Argonne National Lab, IL (United States) (1995).

31. S. M. S. Murshed, K. C. Leong, and C. Yang, International Journal of Thermal Sciences 47, 560 (2008).

32. Q. Li and Y. Xuan, Science in China Series E: Technolgical Science 45, 408 (2002).

33. S. Kakaç and A. Pramuanjaroenkij, Int. J. Heat Mass Transfer 52, 3187 (2009).

34. V. Trisaksri and S. Wongwises, Renewable and Sustainable Energy Reviews 11, 512 (2007)

35. A. Nasiri, Shariaty-M. Niasar, A. M. Rashidi, and R. Khodafarin, Int. J. Heat Mass Transfer 55, 1529 (2012).
36. S. M. S. Murshed, K. C. Leong, and C. Yang, International Journal of Thermal Sciences 44, 367 (2005).

37. A. K. Tiwari, P. Ghosh, J. Sarkar, H. Dahiya, and J. Parekh, International Journal of Thermal Sciences 85, 93 (2014).

38. V. Wagner, A. Dullaart, A. K. Bock, and A. Zweck, Nat. Biotechnol. 24, 1211 (2006)

39. https://www.shutterstock.com/image-vector/blood-vessels-types-humancirculatory-system-1536128441

40. R. Saidur, K. Y. Leong, and H. A. Mohammed, Renewable and Sustainable Energy Reviews 15, 1646 (2011).

41. L. Godson, B. Raja, D. M. Lal, and S. E. A. Wongwises, Renewable and Sustainable Energy Reviews 14, 629 (2010).

42. J. Sarkar, Renewable and Sustainable Energy Reviews 15, 3271 (2011)

43. W. Daungthongsuk and S. Wongwises, Renewable and Sustainable Energy Reviews 11, 797 (2007)

44. A. K. Tiwari, P. Ghosh, and J. Sarkar, Appl. Therm. Eng. 57, 24 (2013)

45. T. A. Kumar, G. Pradyumna, and S. Jahar, Journal of Environmental Research and Development 7 (2012).

46. D. H. Babu, K. A. Ajmath, B. Venkateswarlu, and P. V. Narayana, Journal of Nanofluids 8, 1085 (2019).

47. H. Chen and Y. Ding, Heat transfer and rheological behaviour of nanofluids-A review. In Advances in Transport Phenomena, Springer, Berlin, Heidelberg (2009), pp. 135-177.

48. W. Duangthongsuk and S. Wongwises, Int. J. Heat Mass Transfer 53, 334 (2010)

49. M. M. Heyhat, F. Kowsary, A. M. Rashidi, M. H. Momenpour, and A. Amrollahi, Experimental Thermal and Fluid Science 44, 483 (2013)

50. J. Bayat and A. H. Nikseresht, International Journal of Thermal Sciences 60, 236 (2012).

51. A. A. Arani and J. Amani, Experimental Thermal and Fluid Science 42, 107 (2012)

52. B. C. Pak and Y. I. Cho, Experimental Heat Transfer an International Journal 11, 151 (1998).

53. R. L. Hamilton and O. K. Crosser, Industrial and Engineering Chemistry Fundamentals 1, 187 (1962)

54. J. C. Maxwell, A Treatise on Electricity and Magnetism, Clarendon Press, Oxford (1873), Vol. 1.

55. A. Einstein, Ann. Phys. 19, 289 (1906).

56. H. C. Brinkman, J. Chem. Phys. 20, 571 (1952)

57. S. K. Das, S. U. Choi, W. Yu, and T. Pradeep, Nanofluids: Science and Technology, John Wiley \& Sons (2007).

58. Y. Xuan and W. Roetzel, Int. J.Heat Mass Transfer 43, 3701 $\underline{(2000)}$

59. J. A. Eastman, S.U. S. Choi, S. Li, G. Soyez, L. J. Thompson, and R. J. Di Melfi, Material Science Forum; 312-314, 629 (1999).

60. S. J. Palm, G. Roy, and C. T. Nguyen, Appl. Therm. Eng. 26, 2209 (2006)

61. A. Makishima, Ceram. Jap. 39, 90 (2004).

62. T. Hayat and S. Nadeem, Results in Physics 7, 2317 (2017)

63. F. Selimefendigil and H. F. Öztop, Int. J. Heat Mass Transfer 117, 331 (2018)

64. D. Madhesh and S. Kalaiselvam, Journal of Experimental Nanoscience 10, 1194 (2015).

65. S. Manikandan and K. S. Rajan, Energy Conversion and Management 137, 74 (2017)

66. O. Mahian, L. Kolsi, M. Amani, P. Estellé, G. Ahmadi, C. Kleinstreuer, J. S. Marshall, M. Siavashi, R. A. Taylor, H. Niazmand, and S. Wongwises, Physics Reports 790, 1 (2019)

67. K. Khanafer, K. Vafai, and M. Lightstone, Int. J. Heat Mass Transfer 46, 3639 (2003). 
68. E. J. Wasp, J. P. Kenny, and R. L. Gandhi, Solid-liquid flow: Slurry pipeline transportation [Pumps, valves, mechanical equipment, economics]. United States.

69. M. Akhtari, M. Haghshenasfard, and M. R. Talaie, Numerical Heat Transfer, Part A: Applications 63, 941 (2013).

70. G. Saha and M. C. Paul, International Communications in Heat and Mass Transfer 93, 48 (2018).

71. M. Izadi, A. Behzadmehr, and D. Jalali-Vahida, International Journal of Thermal Sciences 48, 2119 (2009).

72. O. Abouali and G. Ahmadi, Appl. Therm. Eng. 36, 1 (2012).

73. Y. Xuan and W. Roetzel, Int. J. Heat Mass Transfer 43, 3701 (2000).

74. M. Bahiraei and S. M. Hosseinalipour, Journal of Dispersion Science and Technology 34, 1778 (2013).

75. S. Kumar, S. K. Prasad, and J. Banerjee, Applied Mathematical Modelling 34, 573 (2010).

76. S. Özerinç, A. G. Yazıcıoğlu, and S. Kakaç, International Journal of Thermal Sciences 62, 138 (2012).

77. M. Ameri, M. Amani, and P. Amani, Adv. Powder Technol. 28, 2747 (2017).

78. M. S. Mojarrad, A. Keshavarz, and A. Shokouhi, Heat Mass Transfer 49, 1333 (2013).

79. J. Buongiorno, ASME, Journal of Heat Transfer 128, 240 (2006).

80. B. Vasu, R. S. R. Gorla, O. A. Bég, P. V. S. N. Murthy, V. R. Prasad, and A. Kadir, Journal of Thermophysics and Heat Transfer 33, 343 (2019).

81. B. Vasu, R. S. Gorla, P. V. S. N. Murthy, and V. R. Prasad, 20th Australasian Fluid Mechanics Conference, Perth, December (2016), pp. 5-8.

82. F. Garoosi, L. Jahanshaloo, M. M. Rashidi, A. Badakhsh, and M. E. Ali, Appl. Math. Comput. 254, 183 (2015).

83. F. Garoosi, S. Garoosi, and K. Hooman, Powder Technol. 268, 279 (2014).

84. A. K. Ray, B. Vasu, O. A. Bég, R. S. Gorla, and P. V. S. N. Murthy, Inventions 4, 54 (2019).

85. B. Vasu, R. S. R. Gorla, P. V. S. N. Murthy, and O. A. Bég, Journal of Applied Mechanics and Technical Physics 60, 827 (2019).

86. R. S. R. Gorla, B. Vasu, and S. Siddiqa, Journal of Applied Mathematics and Physics 4, 443 (2016).

87. R. S. R. Gorla and B. Vasu, Journal of Nanofluids 5, 581 (2016).

88. B. Vasu, A. Dubey, O. A. Bég, and R. S. R. Gorla, Computers in Biology and Medicine 126, 104025 (2020).

89. A. Malvandi, S. A. Moshizi, E. G. Soltani, and D. D. Ganji, Computers and Fluids 89, 124 (2014).

90. M. A. Sheremet and I. Pop, Int. J. Heat Mass Transfer 79, 137 (2014).

91. A. Malvandi and D. D. Ganji, Powder Technol. 263, 37 (2014).

92. Y. Xuan and Q. Li, Int. J. Heat Fluid Flow 21, 58 (2000).

93. S. Kakaç and A. Pramuanjaroenkij, Journal of Engineering Physics and Thermophysics 89, 758 (2016).

94. M. Akbari, N. Galanis, and A. Behzadmehr, International Journal of Thermal Sciences 50, 1343 (2011).

95. M. M. Rashidi, A. Hosseini, I. Pop, S. Kumar, and N. Freidoonimehr, Applied Mathematics and Mechanics 35, 831 (2014).

96. R. Davarnejad and M. Jamshidzadeh, Engineering Science and Technology, an International Journal 18, 536 (2015).

97. O. Ghaffari, A. Behzadmehr, and H. Ajam, Int. Commun. Heat Mass Transf. 37, 1551 (2010).
98. S. M. Vanaki, P. Ganesan, and H. A. Mohammed, Renewable and Sustainable Energy Reviews 54, 1212 (2016).

99. H. Safikhani, A. Abbassi, A. Khalkhali, and M. Kalteh, Heat Transfer-Asian Research 44, 377 (2015).

100. M. N. Labib, M. J. Nine, H. Afrianto, H. Chung, and H. Jeong, International Journal of Thermal Sciences 71, 163 (2013).

101. M. Goodarzi, M. R. Safaei, K. Vafai, G. Ahmadi, M. Dahari, S. N. Kazi, and N. Jomhari, International Journal of Thermal Sciences 75, 204 (2014).

102. R. Y. Emami, M. Siavashi, and G. S. Moghaddam, Adv. Powder Technol. 29, 519 (2018).

103. M. Siavashi and A. Rostami, International Journal of Mechanical Sciences 133, 689 (2017).

104. P. Maghsoudi and M. Siavashi, J. Therm. Anal. Calorim. 135, 947 (2019).

105. M. K. Moraveji and R. M. Ardehali, Int. Commun. Heat Mass Transf. 44, 157 (2013).

106. R. Lotfi, Y. Saboohi, and A. M. Rashidi, Int. Commun. Heat Mass Transf. 37, 74 (2010).

107. O. A. Beg, M. M. Rashidi, M. Akbari, and A. Hosseini, Journal of Mechanics in Medicine and Biology 14, 1450011 (2014).

108. M. Hejazian, M. K. Moraveji, and A. Beheshti, Int. Commun. Heat Mass Transf. 52, 152 (2014)

109. E. Ebrahimnia-Bajestan, M. C. Moghadam, H. Niazmand, W. Daungthongsuk, and S. Wongwises, Int. J. Heat Mass Transfer 92, 1041 (2016).

110. R. M. C. Mourad Rebay and Sadik Kaka, Microscale and Nanoscale Heat Transfer: Analysis, Design, and Application, 1st ed., Taylor \& Francis Group, Boca Raton (2016).

111. S. Rashidi, J. A. Esfahani, and R. Ellahi, Applied Sciences 7, 431 (2017).

112. I. M. Mahbubul, Preparation, Characterization, Properties, and Application of Nanofluid, Elsevier, Cambridge, MA (2018).

113. M. Sheikholeslami and D. D. Ganji, Applications of SemiAnalytical Methods for Nanofluid Flow and Heat Transfer, Elsevier (2018).

114. R. Chand ed., Nanofluid Technologies and Thermal Convection Techniques, IGI Global, USA (2017)

115. D. Toghraie, V. A. Chaharsoghi, and M. Afrand, J. Therm. Anal. Calorim. 125, 527 (2016).

116. M. Amiri, S. Movahedirad, and F. Manteghi, Appl. Therm. Eng. 108, 48 (2016).

117. N. N. Esfahani, D. Toghraie, and M. Afrand, Powder Technol. 323, 367 (2018)

118. M. S. Kumar, V. Vasu, and A. V. Gopal, Journal of the Taiwan Institute of Chemical Engineers 66, 321 (2016)

119. M. H. Esfe, A. A. A. Arani, R. S. Badi, and M. Rejvani, J. Therm. Anal. Calorim. 131, 2381 (2018)

120. S. Aberoumand and A. Jafarimoghaddam, Alexandria Engineering Journal 57, 169 (2018).

121. S. H. Rostamian, M. Biglari, S. Saedodin, and M. H. Esfe, J. Mol. Liq. 231, 364 (2017).

122. S. Akilu, A. T. Baheta, and K. V. Sharma, J. Mol. Liq. 246, 396 (2017).

123. S. H. Qing, W. Rashmi, M. Khalid, T. C. S. M. Gupta, M. Nabipoor, and M. T. Hajibeigy, Materials Research Express 4, 015504 (2017).

124. A. Parsian and M. Akbari, J. Therm. Anal. Calorim. 131, 1605 (2018).

125. A. Asadi, M. Asadi, A. Rezaniakolaei, L. A. Rosendahl, M. Afrand, and S. Wongwises, Int. J. Heat Mass Transfer 117, 474 (2018).

126. M. F. Nabil, W. H. Azmi, K. A. Hamid, R. Mamat, and F. Y. Hagos, Int. Commun. Heat Mass Transf. 86, 181 (2017).

127. W. R. Richmond, R. L. Jones, and P. D. Fawell, Chem. Eng. J. 71, 67 (1998) 
128. W. J. Tseng and K. C. Lin, Mater. Sci. Eng., A 355,186 (2003).

129. Y. He, Y. Jin, H. Chen, Y. Ding, D. Cang, and H. Lu, Int. J. Heat Mass Transfer 50, 2272 (2007)

130. H. Chen, Y. Ding, and C. Tan, New J. Phys. 9, 367 (2007).

131. H. Chen, Y. Ding, Y. He, and C. Tan, Chem. Phys. Lett. 444, 333 (2007).

132. P. Alphonse, R. Bleta, and R. Soules, J. Colloid Interface Sci. 337, 81 (2009).

133. J. Chevalier, O. Tillement, and F. Ayela, Appl. Phys. Lett. 91, 233103 (2007)

134. K. Anoop, R. Sadr, Al-M. Jubouri, and M. Amani, International Journal of Thermal Sciences 77, 108 (2014).

135. W. J. Tseng and C. H. Wu, Ceram. Int. 29, 821 (2003).

136. M. J. Pastoriza-Gallego, L. Lugo, J. L. Legido, and M. M. Piñeiro, Nanoscale Research Letters 6, 1 (2011).

137. K. Y. Kwak and C. Y. Kim, Korea-Australia Rheology Journal 17, 35 (2005).

138. M. T. Naik, G. R. Janardhana, K. V. K. Reddy and B. S. Reddy, ARPN J. Eng. Appl. Sci. 5, 29 (2010).

139. M. Saeedinia, M. A. Akhavan-Behabadi, and P. Razi, Int. Commun. Heat Mass Transf. 39, 152 (2012).

140. B. Wang, X. Wang, W. Lou, and J. Hao, Colloids and Surfaces A: Physicochemical and Engineering Aspects 414, 125 (2012).

141. F. Duan, T. F. Wong, and A. Crivoi, Nanoscale Research Letters 7, 1 (2012).

142. M. B. Moghaddam, E. K. Goharshadi, M. H. Entezari, and P. Nancarrow, Chem. Eng. J. 231, 365 (2013).

143. P. Pötschke, T. D. Fornes, and D. R. Paul, Polymer 43, 3247 (2002).

144. Y. Yang, E. A. Grulke, Z. G. Zhang, and G. Wu, J.Appl. Phys. 99, 114307 (2006)

145. A. T. Seyhan, F. H. Gojny, M. Tanoğlu, and K. Schulte, Eur. Polym. J. 43, 2836 (2007)

146. K. Lu, Powder Technol. 177, 154 (2007).

147. T. X. Phuoc, M. Massoudi, and R. H. Chen, International Journal of Thermal Sciences 50, 12 (2011).

148. B. Ruan and A. M. Jacobi, Nanoscale Research Letters 7, 1 (2012).

149. J. Wang, J. Zhu, X. Zhang, and Y. Chen, Experimental Thermal and Fluid Science 44, 716 (2013).

150. H. Chen, S. Witharana, Y. Jin, C. Kim, and Y. Ding, Particuology 7, 151 (2009).

151. P. Alphonse, R. Bleta, and R. Soules, J. Colloid Interface Sci. 337, 81 (2009).

152. M. Hojjat, S. G. Etemad, R. Bagheri, and J. Thibault, Int. Commun. Heat Mass Transf. 38, 144 (2011).

153. I. Tavman, A. Turgut, M. Chirtoc, H. P. Schuchmann, and S. Tavman, Archives of Materials Science 100 (2008).

154. Y. Jung, Y. H. Son, J. K. Lee, T. X. Phuoc, Y. Soong, and M. K. Chyu, ACS Applied Materials and Interfaces 3, 3515 (2011).

155. W. J. Tseng and S. Y. Li, Mater. Sci. Eng., A 333,314 (2002).

156. W. J. Tseng and C. N. Chen, Mater. Sci. Eng., A 347, 145 (2003).

157. B. Mary, C. Dubois, P. J. Carreau, and P. Brousseau, Rheologica acta 45, 561 (2006)

158. E. Tamjid and B. H. Guenther, Powder Technol. 197, 49 (2010)

159. W. J. Tseng and F. Tzeng, Colloids and Surfaces A: Physicochemical and Engineering Aspects 276, 34 (2006).

160. H. Zhu, C. Li, D. Wu, C. Zhang, and Y. Yin, Science China Technological Sciences 53, 360 (2010).
161. H. Xie, W. Yu, and W. Chen, Journal of Experimental Nanoscience 5, 463 (2010)

162. Z. Meng, D. Han, D. Wu, H. Zhu, and Q. Li, Procedia Engineering 36, 521 (2012)

163. M. Cholewa, G. Żyła, A. Witek, J. P. Plog, V. Lehmann, T. Oerther, and D. Gross, Archives of Mechanics 65, 131 (2013).

164. R. Y. Hong, T. T. Pan, Y. P. Han, H. Z. Li, J. Ding, and S. Han, J. Magn. Magn. Mater. 310, 37 (2007).

165. M. T. Zafarani-Moattar and R. Majdan-Cegincara, Colloid. Polym. Sci. 291, 1977 (2013).

166. T. X. Phuoc and M. Massoudi, International Journal of Thermal Sciences 48, 1294 (2009).

167. M. J. Pastoriza-Gallego, L. Lugo, J. L. Legido, and M. M. Piñeiro, Nanoscale Research Letters 6, 1 (2011).

168. M. Abareshi, S. H. Sajjadi, S. M. Zebarjad, and E. K. Goharshadi, J. Mol. Liq. 163, 27 (2011).

169. L. Vékás, O. Marinică, D. Susan-Resiga, F. D. Stoian, and D. Bica, Proceedings of the 6th International Conference on Hydraulic Machinery and Hydrodynamics, HMH2004 Romania, October (2004), pp. 685-92.

170. D. Susan-Resiga, V. Socoliuc, T. Boros, T. Borbáth, O. Marinica A. Han, and L. Vékás, J. Colloid Interface Sci. 373, 110 (2012).

171. A. Katiyar, A. N. Singh, P. Shukla, and T. Nandi, Powder Technol. 224, 86 (2012)

172. S. Chakravarty and P. K. Mandal, Mathematical and Computer Modelling 19, 59 (1994).

173. P. K. Mandal, (2005). International Journal of Non-Linear Mechanics 40,151

174. S. Chakravarty and P. K. Mandal, International Journal of NonLinear Mechanics 35, 779 (2000).

175. D. Tripathi, Journal of Bionic Engineering 9, 119 (2012).

176. R. Naz, F. M. Mahomed, and D. P. Mason, Appl. Math. Comput. 205, 212 (2008).

177. P. K. Shukla and H. U. Rahman, Physica Scripta 57, 286 (1998).

178. M. Hameed and R. Ellahi, International Journal for Numerical Methods in Fluids 66, 1409 (2011).

179. R. Ellahi, A. Riaz, S. Nadeem, and M. Ali, Mathematical Problems in Engineering 2012 (2012).

180. S. Nadeem and N. S. Akbar, Communications in Nonlinear Science and Numerical Simulation 14, 4100 (2009).

181. S. Nadeem, N. S. Akbar, A. A. Hendi, and T. Hayat, Appl. Math. Comput. 217, 71082011

182. K. S. Mekheimer and M. A. El Kot, Applied Mathematical Modelling 36, 5393 (2012).

183. K. S. Mekheimer, M. H. Haroun, and M. A. El Kot, Appl. Math. 6, 281 (2012)

184. D. N. Riahi, R. Roy, and S. Cavazos, Mathematical and Computer Modelling 54, 2999 (2011)

185. R. Ellahi, S. U. Rahman, M. M. Gulzar, S. Nadeem, and K. Vafai, Applied Mathematics and Information Sciences 8, 1567 (2014).

186. R. K. Srivastav, Applications and Applied Mathematics 9 (2014).

187. V. P. Srivastava and R. Srivastava, Computers and Mathematics with Applications 58, 227 (2009).

188. O. A. Bég, V. R. Prasad, and B. Vasu, Journal of Mechanics in Medicine and Biology 13, 1350067 (2013).

189. N. S. Akbar, D. Tripathi, and O. A. Bég, The European Physical Journal Plus 132, 1 (2017).

190. M. Sharma, B. K. Sharma, R. K. Gaur, and B. Tripathi, Journal of Nanofluids 8, 327 (2019).

191. M. M. Bhatti, M. A. Abbas, and M. M. Rashidi, Journal of Nanofluids 5, 920 (2016). 
192. D. Srinivasacharya and G. Madhava Rao, Journal of Nanofluids 5,774 (2016).

193. I. Abdullah, N. Amin, and T. Hayat, International Journal for Numerical Methods in Fluids 67, 1624 (2011).

194. N. Mustapha, P. K. Mandal, P. R. Johnston, and N. Amin, Applied Mathematical Modelling 34, 1559 (2010).

195. R. Ellahi, Ur-S. Rahman, and S. Nadeem, Zeitschrift für Naturforschung A 68, 489 (2013).

196. N. Ali, A. Zaman, and M. Sajid, Computers and Fluids 101, 42 (2014).

197. R. Ellahi, S. U. Rahman, S. Nadeem, and N. S. Akbar, Applied Nanoscience 4, 919 (2014).

198. S. Nadeem and S. Ijaz, AIP Advances 5, 107217 (2015).

199. A. Ahmed and S. Nadeem, J. Mol. Liq. 216, 615 (2016).

200. K. S. Mekheimer, T. Elnaqeeb, M. A. El Kot, and F. Alghamdi, Physics Essays 29, 272 (2016).

201. S. Nadeem and S. Ijaz, IEEE Transactions on Nanobioscience 14, 668 (2015).

202. N. S. Akbar, S. Nadeem, and K. S. Mekheimer, Journal of the Egyptian Mathematical Society 24, 138 (2016).

203. T. Elnaqeeb, K. S. Mekheimer, and F. Alghamdi, Mathematical biosciences 282, 135 (2016).

204. A. H. Talib, I. Abdullah, and I. Sabri, AIP Conference Proceedings 1870, 040062 (2017).

205. A. Ahmed and S. Nadeem, Results in physics 7, 677 (2017).

206. S. Ijaz and S. Nadeem, The European Physical Journal Plus 132, 1 (2017).

207. S. Changdar and S. De, Iranian Journal of Science and Technology, Transactions A: Science 43, 1259 (2019).

208. R. Ponalagusamy and S. Priyadharshini, Korea-Australia Rheology Journal 29, 303 (2017).

209. A. Ahmed and S. Nadeem, Results in Physics A, 4130 (2017).

210. S. Ijaz, Z. Iqbal, E. N. Maraj, and S. Nadeem, J. Mol. Liq. 254, 421(2018).

211. N. Ali, A. Zaman, M. Sajid, O. A. Bég, M. D. Shamshuddin, and A. Kadir, Nanoscience and Technology: An International Journal 9 (2018).
212. A. Zaman, N. Ali, and I. Ali, Thermal Science and Engineering Progress 5, 482 (2018).

213. S. Priyadharshini and R. Ponalagusamy, International Journal of Applied and Computational Mathematics 5, 1 (2019).

214. S. Ijaz and S. Nadeem, J. Mol. Liq. 248, 809 (2017).

215. I. Shahzadi and N. Kousar, Computer Methods and Programs in Biomedicine 179, 104980 (2019).

216. S. Changdar and S. De, Journal of Nanofluids 6, 87 (2017).

217. R. Padma, R. T. Selvi, and R. Ponalagusamy, The European Physical Journal Plus 134, 221 (2019).

218. F. Sultan, N. A. Khan, M. Qasim, and M. I. Afridi, Nihon Reoroji Gakkaishi 47, 75 (2019).

219. B. Vasu, A. Dubey, and O. A. Bég, Heat Transfer-Asian Research 49, 33 (2020).

220. A. Dubey, B. Vasu, Anwar O. Beg, R. S. Gorla, and A. Kadir, Computer Methods in Biomechanics and Biomedical Engineering 23, 345 (2020).

221. S. Changdar, A. K. Mandal, and S. De, Journal of Nanofluids 7, 1187 (2018).

222. S. I. Abdelsalam, K. S. Mekheimer, and A. Z. Zaher, Chinese Journal of Physics 67, 314 (2020).

223. P. Devaki, B. Venkateswarlu, S. Srinivas, and S. Sreenadh, Nonlinear Engineering 9, 51 (2019).

224. T. Elnaqeeb, N. A. Shah, and K. S. Mekheimer, BioNanoScience 9, 245 (2019).

225. I. Shahzadi and S. Bilal, Computer Methods and Programs in Biomedicine 187, 105248 (2020).

226. T. Elnaqeeb, The European Physical Journal Special Topics 228, 2695 (2019).

227. F. Karami, A. A. Nadooshan, and Y. T. Beni, Heat Mass Transfer 56,459 (2020).

228. S. R. Yan, M. Zarringhalam, D. Toghraie, L. K. Foong, and P. Talebizadehsardari, Computer Methods and Programs in Biomedicine 192, 105434 (2020)

229. A. Karimipour, D. Toghraie, L. A. Abdulkareem, A. A. Alizadeh, M. Zarringhalam, and A. Karimipour, Medical Hypotheses 144, 109864 (2020). 